\title{
Dual Porosity and Dual Permeability Modeling of Horizontal Well in Naturally Fractured Reservoir
}

\author{
Ren-Shi Nie • Ying-Feng Meng • Yong-Lu Jia • \\ Fu-Xiang Zhang · Xiang-Tong Yang · Xin-Nian Niu
}

Received: 15 December 2010 / Accepted: 13 October 2011 / Published online: 2 November 2011

(C) The Author(s) 2011. This article is published with open access at Springerlink.com

\begin{abstract}
This article is the first investigation on the dual permeability flow issue for horizontal well-production in a naturally fractured dual-porosity reservoir. Based on the inter-porosity flow from matrix system to fracture system and treating the media directly connected with horizontal wellbore as matrix and fracture systems, we established a model of horizontal well-production and then solved the model using some modern mathematical methods, such as Laplace integral transformation, separation of variables, eigenvalue, and eigenfunction. Later in the article, we obtained the standard log-log type curves using numerical simulation and analyzed the transient flow behavior thoroughly, which showed it is dual porosity and dual permeability flow behavior. The numerical simulation results showed that there are obvious differences between dual permeability and single permeability models. The dual permeability flow behavior accelerates energy supplement during production and reduces the classical matrix-fracture (V-shaped) response. We also showed that type curves characteristics are affected by external boundary conditions, the parameter $\kappa, \omega_{\mathrm{f}}$ and $\lambda_{\mathrm{mf}}$, etc. The research results show that our model would be a good semi-analytical model supplied to users. Because the single permeability modeling ignores the direct fluid supply from matrix to wellbore, we recommend using the dual permeability modeling to make well testing and rate decline interpretation in real case studies.
\end{abstract}

Keywords Naturally fractured reservoir · Horizontal well · Modeling · Dual permeability · Type curves

R.-S. Nie $(\bowtie)$ · Y.-F. Meng · Y.-L. Jia

State Key Laboratory of Oil \& Gas Reservoir Geology and Exploitation, Southwest Petroleum University,

Xindu District, Chengdu 610500, Sichuan, China

e-mail: nierenshi2000@126.com

F.-X. Zhang $\cdot$ X.-T. Yang $\cdot$ X.-N. Niu

Petrochina Tarim Oilfield Company, Kurle, China 


\section{Introduction}

Owing to the complex structure, naturally fractured reservoirs attracted, and challenged research community, such as petroleum engineers, geologists, fluid mechanics, and water resource researches (Braester and Zeitoun 1993; Chen 1989; Chastanet et al. 2007; Li et al. 2010). In the meantime, the flow phenomenon of horizontal well in porous media reservoir has gained more and more interests to the scientists and engineers (Algharaib et al. 2006; Boughrara and Reynolds 2009; Huang et al. 2011; Kawecki 2000; KompaniZare et al. 2005; Langseth et al. 2004; Mattar and Santo 1995; Ozkan 2001; Peres and Reynolds 2003; Sherrard 1995; Sun and Zhan 2006; Zhan and Zlotnik 2002). Naturally fractured reservoirs are structured by matrix system and fracture system. The development of fractures differs across reservoirs, so each reservoir has a distinct set of fluid transport behaviors (Braester 1984). Therefore, a vital task for researchers is to establish various test models for the industry to evaluate the properties of underground reservoirs (Corbett et al. 2010).

The flow issues and basic models about well production in porous media reservoir have been well known and researched during last decade. In general, there have 4 theoretical models: (1) Dual porosity and single permeability models for naturally fractured reservoirs, such as some analytical models (De Swaan 1976; Jalali and Ershaghi 1987; Warren and Root 1963) and semi-analytical models (Al-Ghamdi and Ershaghi 1996; Bui et al. 2000). These models considered the fracture system as the flow pathway directly connected with wellbore by ignored the flow from matrix system to wellbore, on the other hand, considered the inter-porosity flow from matrix system to fracture system. (2) Dual porosity and dual permeability models for naturally fractured reservoirs, such as analytical model (Hu and Huang 2002), semi-analytical model (Van Heel et al. 2008) and numerical models (Al-Shaalan et al. 2003; Degraff et al. 2005; Uba et al. 2007). These models considered the fracture and matrix systems as the flow pathway directly connected with wellbore, in addition, considered the inter-porosity flow between matrix and fracture systems. (3) Flow models of horizontal well production in a single medium, such as analytical models (Frick et al. 1996; Goode and Thambynayagam 1987; Kuchuk et al. 1991; Ozkan et al. 1989; Sheng 2008), semi-analytical models (Duan et al. 1998; Kuchuk and Hbashy 1996; Ozkan and Raghavan 1991a,b) and numerical models (Hashemi et al. 2006; Gill and Issaka 2007). In these models, there have various complex boundaries for different porous medium, such as homogeneous media, anisotropic media; (4) Flow models of horizontal well in naturally fractured reservoirs, such as analytical model (Du and Stewart 1992) and semi-analytical models (Ng and Aguilera 1999; Ozkan and Raghavan 1991a,b). These models included the dual porosity-single permeability flow behavior.

Despite there have plenty of literatures on this subject, on one modeling the dual permeability flow behavior of horizontal well-production in naturally fractured reservoirs. In this article, we firstly investigated a dual porosity and dual permeability flow model of horizontal well production in a naturally fractured reservoir. We considered the fracture and matrix systems as the flow pathway directly connected with wellbore, also considered the inter-porosity flow between matrix and fracture systems. For the convenience to establish and solve the mathematical model using semi-analytical method, we adopted some simplified assumptions, such as the sugar cube fractures (Warren and Root 1963) and uniform entry into wellbore (Ozkan and Raghavan 1991a,b). Although these assumptions caused some limitations in numerical techniques, the standard type curves in this article convinced that our model can be a good semi-analytical model for real case study. 
Fig. 1 Naturally fractured reservoir scheme

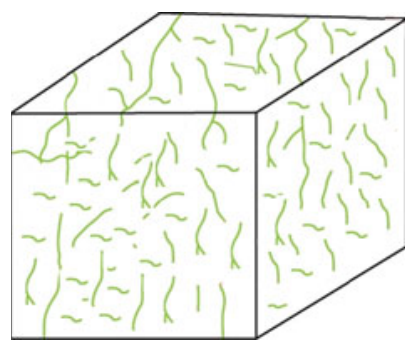

Fig. 2 Horizontal well-scheme in formation

Fig. 3 Dual porosity and dual permeability flow scheme
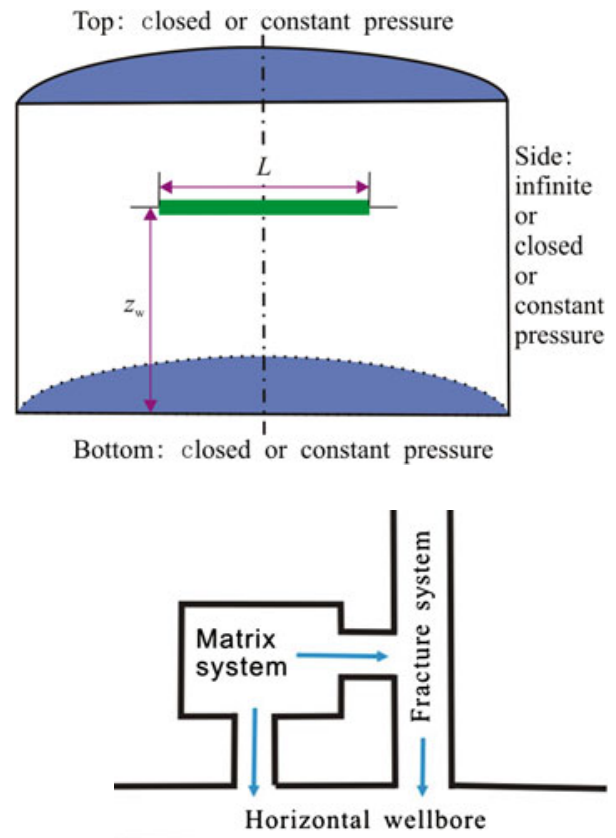

\section{Physical Modeling}

Naturally fractured reservoirs are structured by two systems with relatively independent physical properties, which are matrix system and fracture system (see Fig. 1). Given a single horizontal well-production in a naturally fractured reservoir (see Fig. 2), fluid in the reservoir would flow into wellbore under the pressure drop between wellbore and reservoir pressures, and the dual permeability flow scheme is shown in Fig. 3.

Physical model assumptions are as follows:

(1) Fracture geometry is assumed as the sugar cube fractures in classical dual-porosity (Warren and Root 1963; De Swaan 1976), and the shape of matrix blocks may be arbitrary (different shape with different geometric shape factor $\alpha_{\mathrm{m}}$ ) (Warren and Root 1963; Al-Ghamdi and Ershaghi 1996);

(2) A single horizontal well production at constant rate or at constant wellbore pressure in naturally fractured reservoir, the external boundary of side may be infinite or closed or constant pressure, the external boundaries of top and bottom may be closed or constant pressure (see Fig. 2); 
(3) Fluid entry into wellbore from formation is assumed as uniform as that every point source along wellbore is the same;

(4) Total compressibility (rock and fluid) is low and it is a constant;

(5) Isothermal and Darcy flow is considered;

(6) Wellbore storage effect (in the beginning of opening well, the fluid stored in wellbore starts to flow, the fluid in formation does not flow) only used for constant rate production;

(7) Skin effect (near wellbore, since the formation could be damaged due to drilling and completion operations, there would be an additional pressure drop when well producing, so the "skin" is the reflection of additional pressure drop) used for both constant rate production and constant wellbore pressure production;

(8) At time $t=0$, pressure is homogeneously distributed in reservoir, equal to the initial pressure $p_{\mathrm{i}}$.

\section{Mathematical Modeling}

\subsection{Mathematical Model}

The mathematical modeling has been established in a radial cylindrical system (see Fig. 4). The radial cylindrical system includes a radial coordinate $r$ (see Fig. 4a) and a perpendicular coordinate $z$ (see Fig. 4b). Still, we need a Cartesian coordinate system $(x, y, z)$ (see Fig. 4a-c) and another radial cylindrical system $\left(r^{\prime}, z^{\prime}\right)$ (see Fig. 4d) to establish and solve the mathematical model. Below, we show the mathematical model in detail.

The horizontal well has been treated as a line source composed of finite point sources. First, we seek to the solution of a point source and then obtain the solution of line source

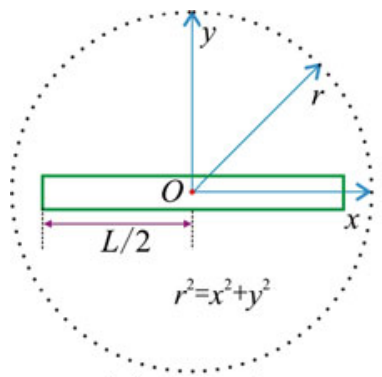

(a) plan view

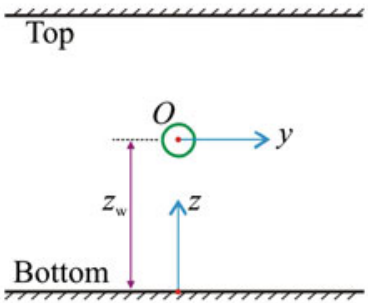

(c) end view

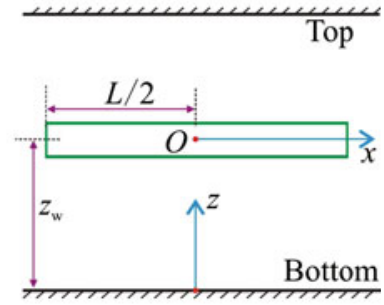

(b) side view

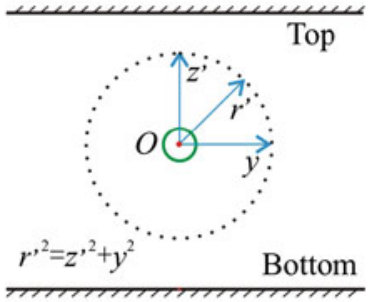

(d) end view

Fig. 4 The views of horizontal well in different coordinate systems 
by superposition integrals to point source solution along the horizontal length (Ozkan and Raghavan 1991a; Duan et al. 1998; Zhan and Zlotnik 2002).

The governing differential equations in radial cylindrical system are these:

i. For fracture system (Ozkan and Raghavan 1991a; Ng and Aguilera 1999)

$$
\left(\frac{\partial^{2} p_{\mathrm{f}}}{\partial r^{2}}+\frac{1}{r} \frac{\partial p_{\mathrm{f}}}{\partial r}+\frac{k_{\mathrm{fp}}}{k_{\mathrm{fh}}} \frac{\partial^{2} p_{\mathrm{f}}}{\partial z^{2}}\right)+\alpha_{\mathrm{m}} \frac{k_{\mathrm{m}}}{k_{\mathrm{fh}}}\left(p_{\mathrm{m}}-p_{\mathrm{f}}\right)=\frac{\mu \phi_{\mathrm{f}} C_{\mathrm{ft}}}{3.6 k_{\mathrm{fh}}} \frac{\partial p_{\mathrm{f}}}{\partial t}
$$

ii. For matrix system

$$
\left(\frac{\partial^{2} p_{\mathrm{m}}}{\partial r^{2}}+\frac{1}{r} \frac{\partial p_{\mathrm{m}}}{\partial r}+\frac{k_{\mathrm{mp}}}{k_{\mathrm{mh}}} \frac{\partial^{2} p_{\mathrm{m}}}{\partial z^{2}}\right)-\alpha_{\mathrm{m}} \frac{k_{\mathrm{m}}}{k_{\mathrm{mh}}}\left(p_{\mathrm{m}}-p_{\mathrm{f}}\right)=\frac{\mu \phi_{\mathrm{m}} C_{\mathrm{mt}}}{3.6 k_{\mathrm{mh}}} \frac{\partial p_{\mathrm{m}}}{\partial t}
$$

Initial condition

$$
\left.p_{\mathrm{f}}\right|_{t=0}=\left.p_{\mathrm{m}}\right|_{t=0}=p_{\mathrm{i}}
$$

Well-production conditions at constant rate production are these:

i. For a point source production:

$$
\widetilde{q}=\lim _{\varepsilon \rightarrow 0}\left[\lim _{r \rightarrow 0} \frac{2 \pi}{\mu \varepsilon} \int_{z_{\mathrm{w}}-\varepsilon / 2}^{z_{\mathrm{w}}+\varepsilon / 2}\left(k_{\mathrm{mh}} r \frac{\partial p_{\mathrm{m}}}{\partial r}+k_{\mathrm{fh}} r \frac{\partial p_{\mathrm{f}}}{\partial r}\right) \mathrm{d} z\right]
$$

ii. For a line source production, the constant rate can be obtained by rate superposition integrals to point source rate along the horizontal length:

$$
q B=\frac{1}{\sigma} \int_{-L / 2}^{L / 2} \tilde{q} \mathrm{~d} x
$$

The wellbore pressure can be obtained by pressure superposition integrals to point source pressure along the horizontal length:

$$
\left.p_{\mathrm{w}}\right|_{r \rightarrow 0}=\frac{1}{\sigma} \int_{-L / 2}^{L / 2} p_{\mathrm{m}}(r, t) \mathrm{d} x=\frac{1}{\sigma} \int_{-L / 2}^{L / 2} p_{\mathrm{f}}(r, t) \mathrm{d} x
$$

where, the pressure $p_{\mathrm{m}}$ and $p_{\mathrm{f}}$ represent the pressures of a point source production and the pressure $p_{\mathrm{w}}$ represents the wellbore pressure of a line source production; the rate $\widetilde{q}$ represents the rate of a point source production and the rate $q$ represents the rate of a line source production at wellhead; the $\sigma$ represents the length dimension per unit horizontal wellbore length, the unit of length in Eq. 6 is meter, so $\sigma=1 \mathrm{~m}$.

Well-production condition at constant wellbore pressure production

$$
\begin{aligned}
\lim _{r \rightarrow r_{\mathrm{w}}} p_{\mathrm{m}} & =\lim _{r \rightarrow r_{\mathrm{w}}} p_{\mathrm{f}}=p_{\mathrm{w}} \\
\widetilde{q} & =\lim _{\varepsilon \rightarrow 0}\left[\lim _{r \rightarrow 0} \frac{2 \pi}{\mu \varepsilon} \int_{z_{\mathrm{w}}-\varepsilon / 2}^{z_{\mathrm{w}}+\varepsilon / 2}\left(k_{\mathrm{mh}} r \frac{\partial p_{\mathrm{m}}}{\partial r}+k_{\mathrm{fh}} r \frac{\partial p_{\mathrm{f}}}{\partial r}\right) \mathrm{d} z\right] \\
q B & =\frac{1}{\sigma} \int_{-L / 2}^{L / 2} \widetilde{q} \mathrm{~d} x
\end{aligned}
$$


External boundary conditions:

For top

$$
\begin{aligned}
& \left.\frac{\partial p_{\mathrm{m}}}{\partial z}\right|_{z=h}=\left.\frac{\partial p_{\mathrm{f}}}{\partial z}\right|_{z=h}=0 \quad \text { (closed) } \\
& \left.p_{\mathrm{m}}\right|_{z=h}=\left.p_{\mathrm{f}}\right|_{z=h}=p_{\mathrm{i}} \quad \text { (constant pressure) }
\end{aligned}
$$

For bottom

$$
\begin{aligned}
& \left.\frac{\partial p_{\mathrm{m}}}{\partial z}\right|_{z=0}=\left.\frac{\partial p_{\mathrm{f}}}{\partial z}\right|_{z=0}=0 \quad \text { (closed) } \\
& \left.p_{\mathrm{m}}\right|_{z=0}=\left.p_{\mathrm{f}}\right|_{z=0}=p_{\mathrm{i}} \quad \text { (constant pressure) }
\end{aligned}
$$

For side

$$
\begin{aligned}
& \lim _{r \rightarrow \infty} p_{\mathrm{m}}=\lim _{r \rightarrow \infty} p_{\mathrm{f}}=p_{\mathrm{i}} \quad \text { (infinite) } \\
&\left.p_{\mathrm{m}}\right|_{r=r_{\mathrm{e}}}=\left.p_{\mathrm{f}}\right|_{r=r_{\mathrm{e}}}=p_{\mathrm{i}} \quad \text { (constant pressure) } \\
&\left.\frac{\partial p_{\mathrm{m}}}{\partial r}\right|_{r=r_{\mathrm{e}}}=\left.\frac{\partial p_{\mathrm{f}}}{\partial r}\right|_{r=r_{\mathrm{e}}}=0 \quad \text { (closed) }
\end{aligned}
$$

where $p_{\mathrm{f}}$ and $p_{\mathrm{m}}(\mathrm{MPa})$ are the pressure of fracture and matrix dominated by a point source production, respectively; $p_{\mathrm{w}}(\mathrm{MPa})$ is the wellbore pressure dominated by a line source production; $p_{\mathrm{i}}(\mathrm{MPa})$ is the initial formation pressure; $r(\mathrm{~m})$ is the radial distance; $r_{\mathrm{W}}(\mathrm{m})$ is the real wellbore radius; $r_{\mathrm{e}}(\mathrm{m})$ is the radial distance of side external boundary; $z(\mathrm{~m})$ is the perpendicular distance from bottom; $z_{\mathrm{w}}(\mathrm{m})$ is the perpendicular distance of horizontal well from bottom; $\varepsilon(\mathrm{m})$ is a variable in $z$ direction; $t(\mathrm{~h})$ is the production time; $k_{\mathrm{f}}$ and $k_{\mathrm{m}}\left[\mu \mathrm{m}^{2}\right]$ are the permeabilities of fracture and matrix, respectively; $k_{\mathrm{fp}}$ and $k_{\mathrm{mp}}\left[\mu \mathrm{m}^{2}\right]$ are the perpendicular permeabilities of fracture and matrix, respectively; $k_{\mathrm{fh}}$ and $k_{\mathrm{mh}}\left[\mu \mathrm{m}^{2}\right]$ are the horizontal permeabilities of fracture and matrix, respectively; $\mu[\mathrm{mPa} \mathrm{s}]$ is the fluid viscosity; $\phi_{\mathrm{f}}$ and $\phi_{\mathrm{m}}$ (fraction) are the porosities of fracture and matrix, respectively; $\alpha_{\mathrm{m}}\left[\mathrm{m}^{-2}\right]$ is the geometric shape factor of matrix block; $C_{\mathrm{ft}}$ and $C_{\mathrm{mt}}\left[\mathrm{MPa}^{-1}\right]$ are the total compressibilities of fracture and matrix, respectively; $\widetilde{q}\left[\mathrm{~m}^{3} / \mathrm{d}\right]$ is the production rate from point source dominated by a point source production; $q\left[\mathrm{~m}^{3} / \mathrm{d}\right]$ is the production rate of horizontal well at wellhead dominated by a line source production; $B$ (dimensionless) is the oil volume factor.

\subsection{Dimensionless Mathematical Model}

All kinds of dimensionless definitions are shown in the Appendix A. The main dimensionless differential equations are as follows:

For fracture system

$$
\kappa\left(\frac{\partial^{2} p_{\mathrm{fD}}}{\partial r_{\mathrm{D}}^{2}}+\frac{1}{r_{\mathrm{D}}} \frac{\partial p_{\mathrm{fD}}}{\partial r_{\mathrm{D}}}+\frac{1}{h_{\mathrm{D}}^{2}} \frac{\partial^{2} p_{\mathrm{fD}}}{\partial z_{\mathrm{D}}^{2}}\right)+\lambda_{\mathrm{mf}} \mathrm{e}^{-2 S}\left(p_{\mathrm{mD}}-p_{\mathrm{fD}}\right)=\omega_{\mathrm{f}} \mathrm{e}^{-2 S} \frac{\partial p_{\mathrm{fD}}}{\partial t_{\mathrm{D}}}
$$

For matrix system

$$
(1-\kappa)\left(\frac{\partial^{2} p_{\mathrm{mD}}}{\partial r_{\mathrm{D}}^{2}}+\frac{1}{r_{\mathrm{D}}} \frac{\partial p_{\mathrm{mD}}}{\partial r_{\mathrm{D}}}+\frac{1}{h_{\mathrm{D}}^{2}} \frac{\partial^{2} p_{\mathrm{mD}}}{\partial z_{\mathrm{D}}^{2}}\right)-\lambda_{\mathrm{mf}} \mathrm{e}^{-2 S}\left(p_{\mathrm{mD}}-p_{\mathrm{fD}}\right)=\omega_{\mathrm{m}} \mathrm{e}^{-2 S} \frac{\partial p_{\mathrm{mD}}}{\partial t_{\mathrm{D}}}
$$

Initial condition

$$
\left.p_{\mathrm{fD}}\right|_{t_{\mathrm{D}}=0}=\left.p_{\mathrm{mD}}\right|_{t_{\mathrm{D}}=0}=0
$$


Well-production condition for constant rate production or constant wellbore pressure production

$$
\left.p_{\mathrm{fD}}\right|_{r_{\mathrm{D}}=1}=\left.p_{\mathrm{mD}}\right|_{r_{\mathrm{D}}=1}
$$

For constant rate production

$$
\lim _{r_{\mathrm{D}} \rightarrow 0}\left[\kappa r_{\mathrm{D}} \frac{\partial p_{\mathrm{fD}}}{\partial r_{\mathrm{D}}}+(1-\kappa) r_{\mathrm{D}} \frac{\partial p_{\mathrm{mD}}}{\partial r_{\mathrm{D}}}\right]=-1
$$

For constant wellbore pressure production

$$
\lim _{r_{\mathrm{D}} \rightarrow 0}\left[\kappa p_{\mathrm{fD}}+(1-\kappa) p_{\mathrm{mD}}\right]=1
$$

where: $\kappa$ [dimensionless] is the permeability ratio of fracture system to the sum of fracture and matrix system; $\lambda_{\mathrm{mf}}$ [dimensionless] is the inter-porosity flow factor of matrix into fracture; $\omega_{\mathrm{f}}$ and $\omega_{\mathrm{m}}$ [dimensionless] are the fluid capacitance coefficient of fracture and matrix, respectively; $S$ [dimensionless] is the Skin factor similar to vertical well; $p_{\mathrm{fD}}$ and $p_{\mathrm{mD}}$ are the dimensionless pressure of fracture and matrix, respectively; $r_{\mathrm{D}}$ is the dimensionless radial distance; $z_{\mathrm{D}}$ is the dimensionless perpendicular distance; $h_{\mathrm{D}}$ is the dimensionless formation thickness; $t_{\mathrm{D}}$ is the dimensionless production time.

Introduce the Laplace transform based on $t_{\mathrm{D}}$, that is

$$
L\left[p_{\mathrm{D}}\left(r_{\mathrm{D}}, t_{\mathrm{D}}\right)\right]=\bar{p}_{\mathrm{D}}\left(r_{\mathrm{D}}, u\right)=\int_{0}^{\infty} p_{\mathrm{D}}\left(r_{\mathrm{D}}, t_{\mathrm{D}}\right) \mathrm{e}^{-u t_{\mathrm{D}}} \mathrm{d} t_{\mathrm{D}}
$$

where: $p_{\mathrm{D}}$ is the dimensionless pressure in real space; $\bar{p}_{\mathrm{D}}$ is the dimensionless pressure in Laplace space; $t_{\mathrm{D}}$ is the dimensionless time in real space; $u$ is the time in Laplace space.

The dimensionless mathematical model in Laplace space is as follows:

For fracture system, the governing differential equations in radial cylindrical system

$$
\kappa\left(\frac{\partial^{2} \bar{p}_{\mathrm{fD}}}{\partial r_{\mathrm{D}}^{2}}+\frac{1}{r_{\mathrm{D}}} \frac{\partial \bar{p}_{\mathrm{fD}}}{\partial r_{\mathrm{D}}}+\frac{1}{h_{\mathrm{D}}^{2}} \frac{\partial^{2} \bar{p}_{\mathrm{fD}}}{\partial z_{\mathrm{D}}^{2}}\right)+\lambda \mathrm{mf}^{-2 S}\left(\bar{p}_{\mathrm{mD}}-\bar{p}_{\mathrm{fD}}\right)=u \omega_{\mathrm{f}} \mathrm{e}^{-2 S} \bar{p}_{\mathrm{fD}}
$$

For matrix system, the governing differential equations in radial cylindrical system

$$
(1-\kappa)\left(\frac{\partial^{2} \bar{p}_{\mathrm{mD}}}{\partial r_{\mathrm{D}}^{2}}+\frac{1}{r_{\mathrm{D}}} \frac{\partial \bar{p}_{\mathrm{mD}}}{\partial r_{\mathrm{D}}}+\frac{1}{h_{\mathrm{D}}^{2}} \frac{\partial^{2} \bar{p}_{\mathrm{mD}}}{\partial z_{\mathrm{D}}^{2}}\right)-\lambda_{\mathrm{mf}} \mathrm{e}^{-2 S}\left(\bar{p}_{\mathrm{mD}}-\bar{p}_{\mathrm{fD}}\right)=u \omega_{\mathrm{m}} \mathrm{e}^{-2 S} \bar{p}_{\mathrm{mD}}
$$

Well production condition for constant rate or constant wellbore pressure production

$$
\left.\bar{p}_{\mathrm{mD}}\right|_{r_{\mathrm{D}}=1}=\bar{p}_{\mathrm{fD}} \mid r_{\mathrm{D}}=1
$$

For constant rate production

$$
\lim _{r_{\mathrm{D}} \rightarrow 0}\left[\kappa r_{\mathrm{D}} \frac{\partial \bar{p}_{\mathrm{fD}}}{\partial r_{\mathrm{D}}}+(1-\kappa) r_{\mathrm{D}} \frac{\partial \bar{p}_{\mathrm{mD}}}{\partial r_{\mathrm{D}}}\right]=-\frac{1}{u}
$$

For constant wellbore pressure production

$$
\lim _{r_{\mathrm{D}} \rightarrow 0}\left[\kappa \bar{p}_{\mathrm{fD}}+(1-\kappa) \bar{p}_{\mathrm{mD}}\right]=\frac{1}{u}
$$

External boundary conditions: 
For top

$$
\begin{aligned}
& \left.\frac{\partial \bar{p}_{\mathrm{mD}}}{\partial z_{\mathrm{D}}}\right|_{z_{\mathrm{D}}=1}=\left.\frac{\partial \bar{p}_{\mathrm{fD}}}{\partial z_{\mathrm{D}}}\right|_{z_{\mathrm{D}}=1}=0 \quad \text { (closed) } \\
& \left.\bar{p}_{\mathrm{mD}}\right|_{z_{\mathrm{D}}=1}=\left.\bar{p}_{\mathrm{fD}}\right|_{z_{\mathrm{D}}=1}=0 \quad \text { (constant pressure) }
\end{aligned}
$$

For bottom

$$
\begin{aligned}
& \left.\frac{\partial \bar{p}_{\mathrm{mD}}}{\partial z_{\mathrm{D}}}\right|_{z_{\mathrm{D}}=0}=\left.\frac{\partial \bar{p}_{\mathrm{fD}}}{\partial z_{\mathrm{D}}}\right|_{z_{\mathrm{D}}=0}=0 \quad \text { (closed) } \\
& \left.\bar{p}_{\mathrm{mD}}\right|_{z_{\mathrm{D}}=0}=\left.\bar{p}_{\mathrm{fD}}\right|_{z_{\mathrm{D}}=0}=0 \quad \text { (constant pressure) }
\end{aligned}
$$

For side

$$
\begin{aligned}
\lim _{r_{\mathrm{D}} \rightarrow \infty} \bar{p}_{\mathrm{mD}} & =\lim _{r_{\mathrm{D}} \rightarrow \infty} \bar{p}_{\mathrm{fD}}=0 \quad \text { (infinite) } \\
\left.\bar{p}_{\mathrm{mD}}\right|_{r_{\mathrm{D}}=r_{\mathrm{eD}}} & =\left.\bar{p}_{\mathrm{fD}}\right|_{r_{\mathrm{D}}=r_{\mathrm{eD}}}=0 \quad \text { (constant pressure) } \\
\left.\frac{\partial \bar{p}_{\mathrm{mD}}}{\partial r_{\mathrm{D}}}\right|_{r_{\mathrm{D}}=r_{\mathrm{eD}}} & =\left.\frac{\partial \bar{p}_{\mathrm{fD}}}{\partial r_{\mathrm{D}}}\right|_{r_{\mathrm{D}}=r_{\mathrm{eD}}}=0 \quad \text { (closed) }
\end{aligned}
$$

\subsection{Solution to Mathematical Model}

By using separation of variables, the model can be solved in horizontal and vertical directions. According to the process of solving the model (see Appendix B), the point source solution in Laplace space for modeling horizontal well-constant rate production can be expressed by

$$
\begin{aligned}
& \bar{p}_{\mathrm{fD}}=\bar{R}_{\mathrm{f}} \cdot \bar{Z}_{\mathrm{f}}=\sum_{n=0}^{\infty} \bar{R}_{\mathrm{f} n} \cdot \bar{Z}_{\mathrm{f} n} \\
& \bar{R}_{\mathrm{f} n}=A_{\mathrm{f} n, 1} \mathrm{I}_{0}\left(\sqrt{\xi_{1 n}} r_{\mathrm{D}}\right)+A_{\mathrm{f} n, 2} \mathrm{I}_{0}\left(\sqrt{\xi_{2 n}} r_{\mathrm{D}}\right)+B_{\mathrm{f} n, 1} \mathrm{~K}_{0}\left(\sqrt{\xi_{1 n}} r_{\mathrm{D}}\right)+B_{\mathrm{f} n, 2} \mathrm{~K}_{0}\left(\sqrt{\xi_{2}} r_{\mathrm{D}}\right) \\
& \xi_{1 n}=\sigma_{1}+\frac{\lambda_{n}}{h_{\mathrm{D}}^{2}}, \xi_{2 n}=\sigma_{2}+\frac{\lambda_{n}}{h_{\mathrm{D}}^{2}}
\end{aligned}
$$

Take a new radial coordinate $r^{\prime}$ around horizontal wellbore and a new perpendicular coordinate $z^{\prime}$ that the origin of coordinate system is the center of wellbore (see Fig. 4d):

$$
\begin{gathered}
r_{\mathrm{D}}^{\prime}=\sqrt{z_{\mathrm{D}}^{\prime 2}+y_{\mathrm{D}}^{2}}=\sqrt{\left(\frac{z_{\mathrm{D}} h-z_{\mathrm{wD}} h}{r_{\mathrm{w}}}\right)^{2}+y_{\mathrm{D}}^{2}}=\sqrt{\left(z_{\mathrm{D}}-z_{\mathrm{wD}}\right)^{2}\left(\frac{h}{r_{\mathrm{w}}}\right)^{2}+y_{\mathrm{D}}^{2}} \\
z_{\mathrm{D}}=\frac{r_{\mathrm{w}}}{h} \sqrt{r_{\mathrm{D}}^{\prime 2}-y_{\mathrm{D}}^{2}}+z_{\mathrm{wD}}
\end{gathered}
$$

At the wall of wellbore:

$$
\begin{gathered}
r=r_{\mathrm{w}}, r_{\mathrm{D}}^{\prime}=1, y_{\mathrm{D}}=0, p_{\mathrm{fD}}=p_{\mathrm{wD}} \\
z_{\mathrm{D}}=\frac{r_{\mathrm{w}}}{h}+z_{\mathrm{wD}}
\end{gathered}
$$

So the dimensionless pressure at the wall of wellbore in Laplace space by superposition integrals to point source solution along the horizontal length (Duan et al. 1998; Ozkan and Raghavan 1991a,b) can be expressed by 
Table 1 Parameters for different external boundaries of top and bottom

\begin{tabular}{|c|c|c|c|c|}
\hline \multicolumn{2}{|c|}{ External boundaries } & \multirow[t]{2}{*}{ Eigenvalue } & \multirow[t]{2}{*}{ Eigenfunction } & \multirow[t]{2}{*}{$\bar{Z}_{\mathrm{W}}\left(\lambda_{n}\right)$} \\
\hline Top & Bottom & & & \\
\hline Closed & Closed & $\lambda_{n}=(n \pi)^{2}$ & $\cos \left(\sqrt{\lambda_{n}} z \mathrm{D}\right)$ & $\frac{1}{2} \cos \left(\sqrt{\lambda_{n}} z_{\mathrm{wD}}\right) \cos \left[\sqrt{\lambda_{n}}\left(\frac{r_{\mathrm{W}}}{h}+z_{\mathrm{wD}}\right)\right]$ \\
\hline $\begin{array}{l}\text { Constant } \\
\text { pressure }\end{array}$ & $\begin{array}{l}\text { Constant } \\
\text { pressure }\end{array}$ & $\lambda_{n}=(n \pi)^{2}$ & $\sin \left(\sqrt{\lambda_{n}} z \mathrm{D}\right)$ & $\frac{1}{2} \sin \left(\sqrt{\lambda_{n}} z_{\mathrm{wD}}\right) \sin \left[\sqrt{\lambda_{n}}\left(\frac{r_{\mathrm{W}}}{h}+z_{\mathrm{wD}}\right)\right]$ \\
\hline Closed & $\begin{array}{l}\text { Constant } \\
\text { pressure }\end{array}$ & $\lambda_{n}=\left[\left(n-\frac{1}{2}\right) \pi\right]^{2}$ & $\sin \left(\sqrt{\lambda_{n}} z \mathrm{D}\right)$ & $\frac{1}{2} \sin \left(\sqrt{\lambda_{n}} z_{\mathrm{wD}}\right) \sin \left[\sqrt{\lambda_{n}}\left(\frac{r_{\mathrm{W}}}{h}+z_{\mathrm{WD}}\right)\right]$ \\
\hline $\begin{array}{l}\text { Constant } \\
\text { pressure }\end{array}$ & Closed & $\lambda_{n}=\left[\left(n-\frac{1}{2}\right) \pi\right]^{2}$ & $\cos \left(\sqrt{\lambda_{n}} z_{\mathrm{D}}\right)$ & $\frac{1}{2} \cos \left(\sqrt{\lambda_{n}} z_{\mathrm{wD}}\right) \cos \left[\sqrt{\lambda_{n}}\left(\frac{r_{\mathrm{W}}}{h}+z_{\mathrm{wD}}\right)\right]$ \\
\hline
\end{tabular}

$$
\begin{gathered}
\bar{p}_{\mathrm{SD}}=\sum_{n=0}^{\infty} \int_{-L / 2 / r_{\mathrm{w}}}^{L / 2 / r_{\mathrm{w}}} \bar{R}_{\mathrm{f}} n\left(x_{\mathrm{D}}, \xi_{1 n}, \xi_{2 n}, \lambda_{n}\right) \mathrm{d} x_{\mathrm{D}} \cdot \bar{Z}_{\mathrm{w}}\left(\lambda_{n}\right) \\
\bar{R}_{\mathrm{fn}}=A_{\mathrm{fn}, 1} \mathrm{I}_{0}\left(\sqrt{\xi_{1 n}} x_{\mathrm{D}}\right)+A_{\mathrm{f} n, 2} \mathrm{I}_{0}\left(\sqrt{\xi_{2 n}} x_{\mathrm{D}}\right)+B_{\mathrm{f} n, 1} \mathrm{~K}_{0}\left(\sqrt{\xi_{1 n}} x_{\mathrm{D}}\right)+B_{\mathrm{f} n, 2} \mathrm{~K}_{0}\left(\sqrt{\xi_{2 n}} x_{\mathrm{D}}\right)
\end{gathered}
$$

The parameters of the perpendicular function $\bar{Z}_{\mathrm{w}}\left(\lambda_{n}\right)$ in Eq. 43 are shown in Table 1 .

When considering wellbore storage for constant rate production, by using Duhamel's principle (Ozkan and Raghavan 1991a,b; Van Everdingen and Hurst 1949), the solution in Laplace space for modeling horizontal well-constant rate production can be obtained by

$$
\bar{p}_{\mathrm{wD}}=\frac{\bar{p}_{\mathrm{sD}}}{1+C_{\mathrm{D}} u^{2} \bar{p}_{\mathrm{sD}}}
$$

where, $\bar{p}_{\mathrm{wD}}$ is the response of a well with storage in Laplace space, $\bar{p}_{\mathrm{SD}}$ is the response of a well without storage in Laplace space.

So the solution in Laplace space for modeling horizontal well-constant wellbore pressure production can be obtained by (Ozkan and Raghavan 1991a,b)

$$
\bar{q}_{\mathrm{D}}=\frac{1}{u^{2} \bar{p}_{\mathrm{sD}}}
$$

\section{Type Curves}

In real space, the dimensionless wellbore pressure $\left(p_{\mathrm{wD}}\right)$ and the derivative $\left(\mathrm{d} p_{\mathrm{wD}} / \mathrm{d} t_{\mathrm{D}}\right)$ can be obtained using Stehfest numerical inversion (Stehfest 1970) to convert $\bar{p}_{\mathrm{wD}}$ back to $p_{\mathrm{wD}}$. Therefore, we can obtain the standard bi-logarithmic type curves of well-test analysis (Nie and Ding 2010) of $p_{\mathrm{wD}}$ and $\left(p^{\prime}{ }_{\mathrm{wD}} \cdot t_{\mathrm{D}} / C_{\mathrm{D}}\right)$ versus $t_{\mathrm{D}} / C_{\mathrm{D}}$. The standard bi-logarithmic type curves of rate decline analysis (Blasingame et al. 1991; Doublet and Blasingame 1994; Marhaendrajana and Blasingame 2001), the $q_{\text {Ddi }}$ and $q_{\text {Ddi }}^{\prime}$ versus $t_{\text {Dd }}$ is similarly obtained.

Type curves interested to the research community (Nie et al. 2011; Zhan and Zlotnik 2002) as they reflect properties of underground reservoirs. Intuitively, type curves graphically show the flow behavior characteristics. In addition, they can be used to make well-test analysis (Bourdet 2002) and rate decline analysis (Blasingame et al. 1991; Doublet and Blasingame 


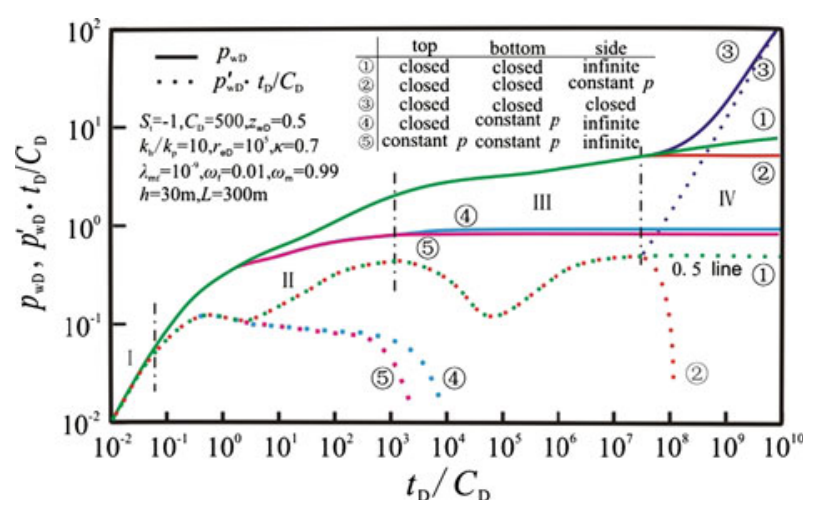

Fig. 5 Type curves of wellbore pressure response

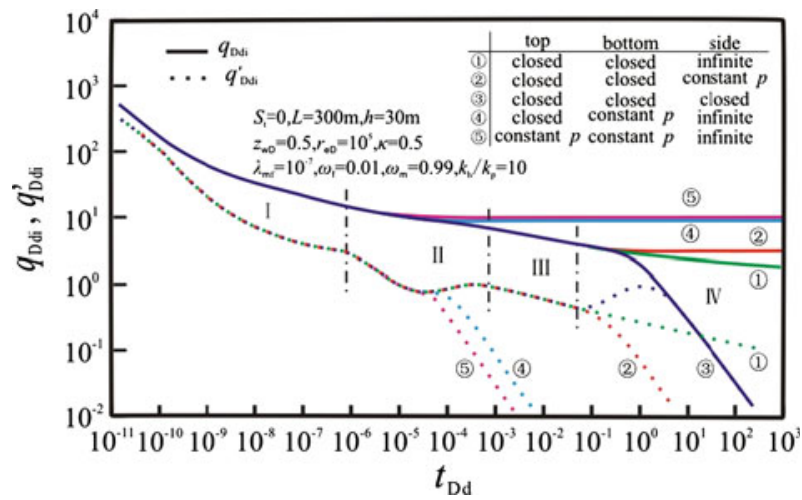

Fig. 6 Type curves of rate decline response

1994) by using curves matching to recognize the flow characteristics for a real reservoir and obtain reservoir property parameters, such as permeability, well-skin factor.

Figures 5-16 show the type curves of wellbore pressure and rate decline dynamic responses for horizontal well with dual porosity and dual permeability modeling in a naturally fractured reservoir. Figures 5 and 6 show the whole transient flow process of horizontal well-production under different external boundaries. In the model, different external boundaries yield different curve shapes (see curves "(1)" "(5)" in Figs. 5 and 6). In the figures, the pressure derivative curves go down early and swiftly (see curves "(4)" and "(5)") because formation thickness is usually much shorter than the horizontal length and the radial distance of side external boundary, therefore, the pressure wave must spread firstly to the constant pressure boundary of top or bottom.

For closed boundary of both top and bottom, an entire transient flow process of a horizontal well-production at a constant rate is clearly shown and the following four main flow stages can be recognized in Fig. 5:

Stage I: Pure wellbore storage stage. The slope of pressure and pressure derivative is one.

Stage II: Skin effect and early transition stage, including early radial flow region and early linear flow region (Chen 1989; Zhan and Zlotnik 2002). The type curves' 
characteristics are the typical response of horizontal well-production. The shape and location of type curves in this stage are affected by the horizontal length $L$, the formation thickness $h$, the ratio of horizontal permeability to perpendicular permeability $k_{h} / k_{\mathrm{p}}$, the relative location of horizontal wellbore in formation $z_{\mathrm{wD}}$ and the skin factor $S$. We only show the type curves characteristics affected by $S$ (see Fig. 15), and the characteristics affected by the parameters $L, h, k_{\mathrm{h}} / k_{\mathrm{p}}$ and $z_{\mathrm{wD}}$ (Duan et al. 1998; Hashemi et al. 2006) are omitted here.

Stage III: Inter-porosity flow stage of matrix system to fracture system. The curve of pressure derivative assumes obviously a $\mathrm{V}$-shaped concave, which is the reflection of the inter-porosity flow of matrix system to fracture system and the typical reflection of dual-porosity media reservoir. The shape and location of V-shaped "concave" are dominated by the permeability ratio of fracture system to the sum of fracture and matrix system $\kappa$, the fluid capacitance coefficient of fracture $\omega_{\mathrm{f}}$ and the inter-porosity flow factor $\lambda_{\mathrm{mf}}$, see Figs.9, 11, and 13.

Stage IV: External boundary response stage. The inter-porosity flow of matrix to fracture has stopped. The pressures between matrix system and fracture system have gone up to a state of dynamic balance. For infinite formation, the slope of pressure derivative curve is zero, and the pressure derivative converges to " 0.5 line", which means the logarithmic value of pressure derivative is 0.5 (see curve "1)"in Fig. 5), so this stage is also called pressure derivative radial flow zero slope stage. For constant pressure boundary, as the pressure derivative curve goes down (see curve "(2)"in Fig. 5), the transient flow would ultimately become steady state flow. For closed boundary, as the pressure derivative curve tilts up (see curve "(3)"in Fig. 5), the transient flow would ultimately become pseudo-steady state flow, in which the type curves converge to a straight line with unit slope.

For closed boundary of both top and bottom, an entire transient flow process of a horizontal well-production at a constant wellbore pressure is clearly showed in Fig. 6. We can also recognize the following four main flow stages:

Stage I: Skin effect and early transition stage, including early radial flow region and early linear flow region.

Stage II: Inter-porosity flow stage of matrix system to fracture system.

Stage III: Whole radial flow region of matrix and fracture systems.

Stage IV: External boundary response stage. The decline rate and its derivative curves ultimately converge to a straight line with negative unit slope for closed external boundary of side, which is the reflection of pseudo-steady state flow.

Given a group of fixed parameters for simulating real case conditions, we can use the theoretical models to calculate the dynamic responses of wellbore pressure and decline rate during production period. Different model would cause different results. It is valuable to make an effective comparison between different models for simulating the same conditions. Fig. 7 and Fig. 8 show the comparisons to type curves between the dual permeability modeling (our modeling) and the single permeability modeling (the Ozkan's modeling) (Ozkan and Raghavan 1991a) for the same group of parameters (see the captions in Figs.7 and 8). Note the parameter $\kappa$ only for the dual permeability modeling.

It can be seen from the figures, there exist obvious differences between stages II and III in Fig. 7, stages I and II in Fig. 8. The location of dimensionless pressure of the dual 


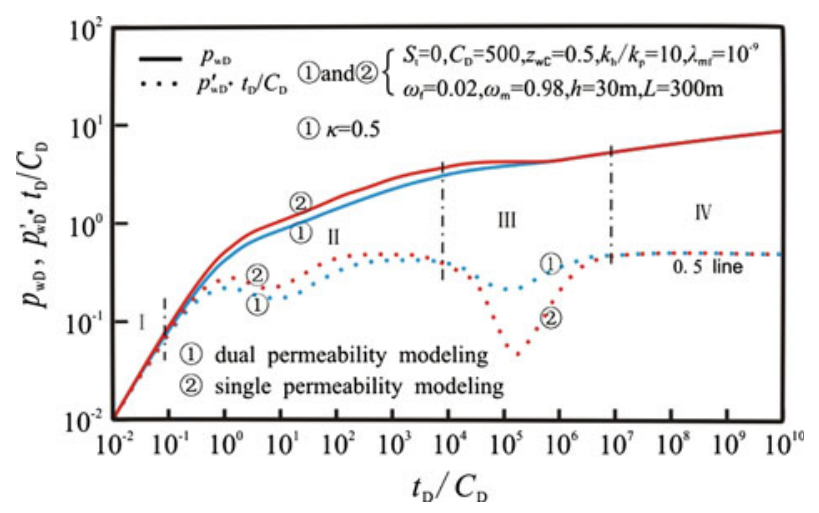

Fig. 7 Compared type curves of wellbore pressure response

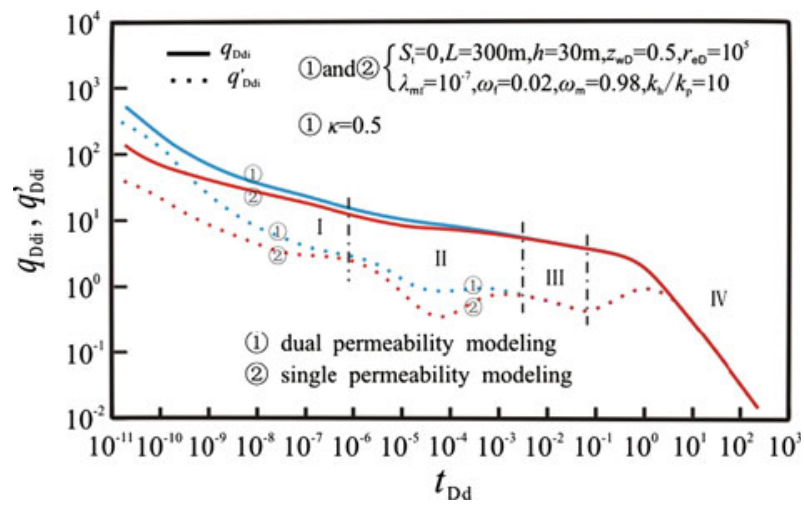

Fig. 8 Compared type curves of rate decline response

permeability modeling is lower than that of the single permeability modeling, which indicates that dual permeability flow accelerates energy supplement during production because the dual permeability modeling considers the direct fluid supply from matrix to wellbore. The V-shaped concave of single permeability modeling in inter-porosity flow stage is deeper than that of dual permeability modeling due to the assumption that the fluid in matrix system completely flows into fracture system in single permeability modeling. So we can say the dual permeability modeling reduces the classical matrix-fracture ( $\mathrm{V}$-shaped) response in single permeability modeling. Of course, there are no differences in pure wellbore storage stage because the fluid in formation is still, and there are no differences in the whole radial flow stage because the inter-porosity from matrix to fracture has stopped and there is a state of dynamic balance between the two systems.

Table 2 exhibits the quantitative differences produced by different physical situations (one is dual permeability flow behavior, and another is single permeability flow behavior). The table shows: (1) in the wellbore storage stage, such as when $t_{D} / C_{D}=10^{-2}$, the calculated value of the pressure using the dual permeability modeling is 0.0093 , which is slightly bigger than the value of the pressure using the single permeability modeling (0.0092), and the difference in calculated results of the pressure derivative is very tiny; (2) in the whole radial flow stage, such as when $t_{D} / C_{D}=10^{8}$ or $t_{D} / C_{D}=10^{10}$, there is no differences 
Table 2 The data comparison between two models

\begin{tabular}{|c|c|c|c|c|c|c|c|c|c|}
\hline \multirow[t]{2}{*}{$t_{\mathrm{D}} / C_{\mathrm{D}}$} & \multicolumn{2}{|l|}{$p_{\mathrm{wD}}$} & \multicolumn{2}{|c|}{$p^{\prime}{ }_{\mathrm{wD}} \cdot t_{\mathrm{D}} / C_{\mathrm{D}}$} & \multirow[t]{2}{*}{$t_{\mathrm{Dd}}$} & \multicolumn{2}{|l|}{$q_{\text {Ddi }}$} & \multicolumn{2}{|l|}{$q_{\text {Ddi }}^{\prime}$} \\
\hline & curve (1) & curve(2) & curve (1) & curve(2) & & curve(1) & curve(2) & curve(1) & curve(2) \\
\hline $10^{-2}$ & 0.0093 & 0.0098 & 0.0092 & 0.0096 & $10^{-10}$ & 187.7417 & 71.8683 & 112.0368 & 19.4647 \\
\hline $10^{0}$ & 0.4371 & 0.5155 & 0.2200 & 0.2806 & $10^{-8}$ & 37.1775 & 27.8888 & 8.1237 & 4.5870 \\
\hline $10^{2}$ & 1.4259 & 1.8446 & 0.3257 & 0.4273 & $10^{-6}$ & 15.9828 & 12.5494 & 2.9828 & 2.4138 \\
\hline $10^{4}$ & 3.3033 & 3.9584 & 0.3929 & 0.3883 & $10^{-4}$ & 8.7328 & 7.8926 & 0.9421 & 0.4056 \\
\hline $10^{6}$ & 4.5925 & 4.6964 & 0.3545 & 0.2033 & $10^{-2}$ & 4.7350 & 4.7392 & 0.5919 & 0.5934 \\
\hline $10^{8}$ & 6.7229 & 6.7229 & 0.5000 & 0.5000 & $10^{0}$ & 1.8181 & 1.8185 & 1.0044 & 1.0044 \\
\hline $10^{10}$ & 9.0264 & 9.0264 & 0.5000 & 0.5000 & $10^{2}$ & 2.7006 & 2.7006 & 0.0302 & 0.0302 \\
\hline
\end{tabular}

in calculated results of the pressure and the pressure derivative can be discerned. While in the other flow stages, such as when $t_{D} / C_{D}=10^{0}, 10^{2}, 10^{4}, 10^{6}$, the distinct differences in calculated results of the pressure and the pressure derivative can be noticed from the table. We can also find the similar differences for the rate dynamic behavior in these flow stages.

In general, what cause those differences is that the single permeability modeling ignored the direct fluid supply from matrix to wellbore. Therefore, we recommend using the dual permeability modeling to make well testing and rate decline interpretation in real case study.

Varying parameters can have significant influence on the shape of type curves, which is due to the fact that well testing analysis is an inverse problem with multiple solutions. In addition, the shape rendered from real data may be distorted by noises, which makes it necessary to establish the stylized shapes under different parameter conditions. Therefore in Figs. $(9,10,11,12,13,14,15,16)$ we showed type curves of a "control group", whose parameters are fixed. Later we will show how the shape of the type curves may be changed by change the parameters. Such investigate is important to both theoretical and empirical researchers.

Figures 9 and 10 show the type curves characteristics affected by parameter $\kappa$. A bigger $\kappa$ leads to a deeper $\mathrm{V}$-shaped concave. The range of $\kappa$ must be zero to one. Base on that, if the $\kappa$ is one the dual permeability modeling of dual media reservoir is reduced to the single

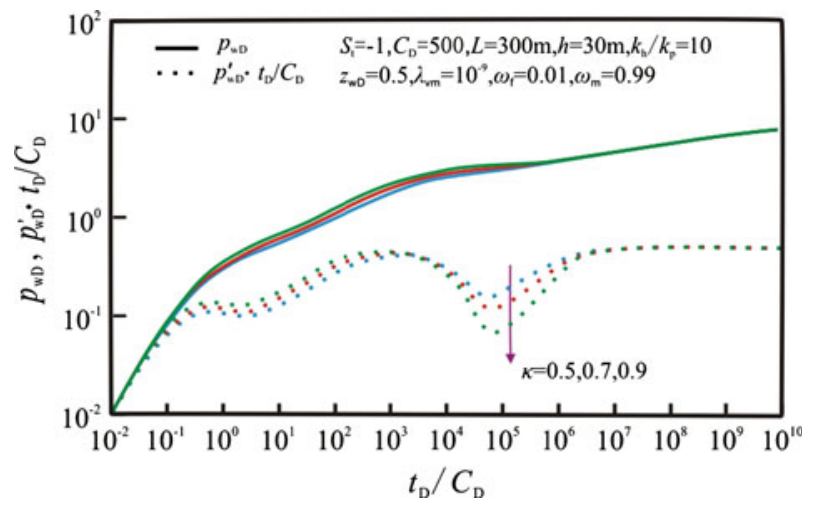

Fig. 9 Type curves of wellbore pressure response affected by $\kappa$ 


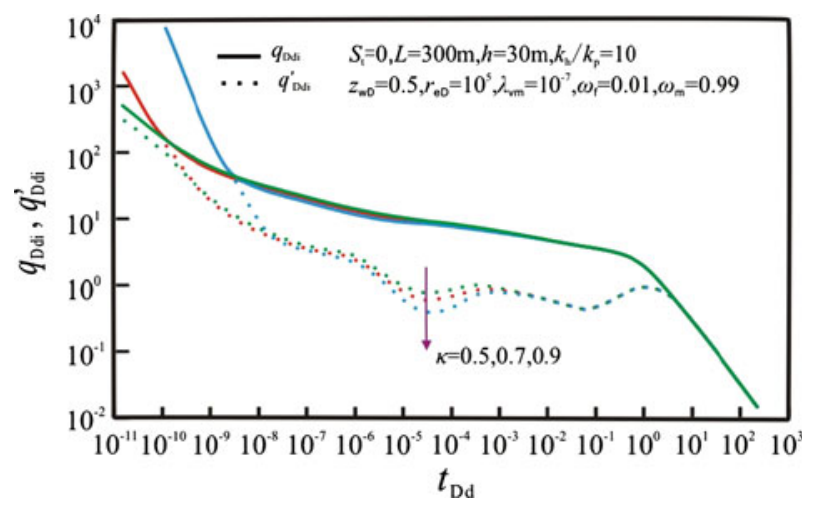

Fig. 10 Type curves of rate decline response affected by $\kappa$

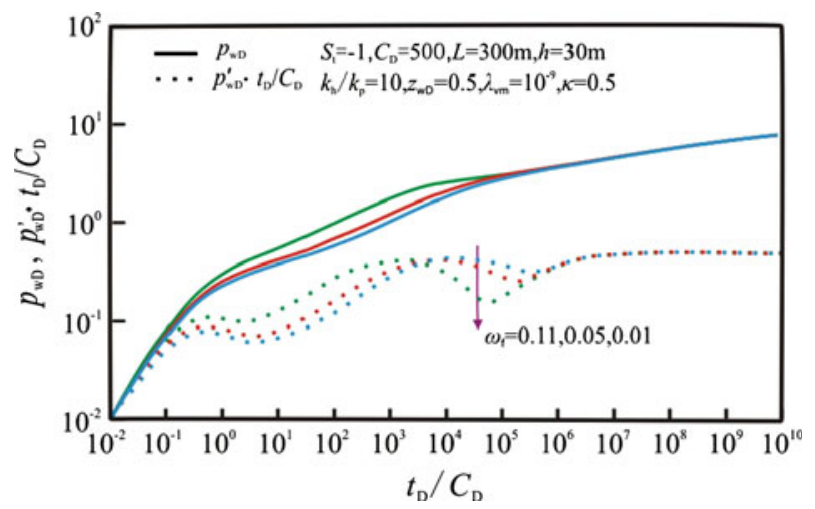

Fig. 11 Type curves of wellbore pressure response affected by $\omega_{\mathrm{f}}$

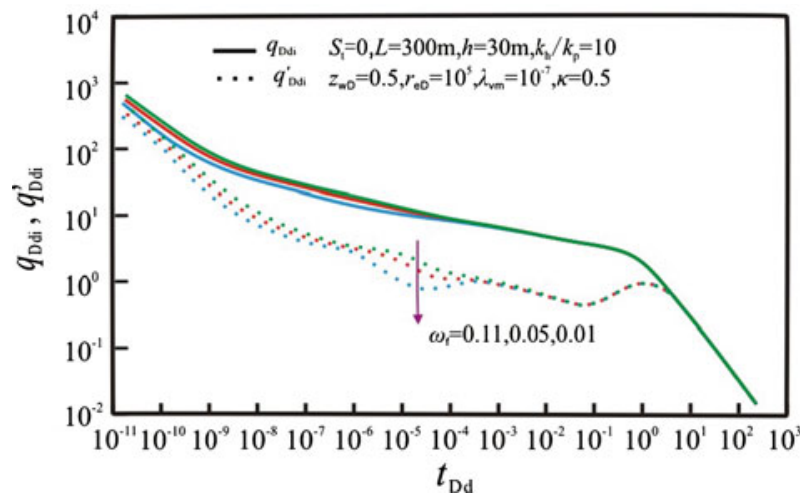

Fig. 12 Type curves of rate decline response affected by $\omega_{\mathrm{f}}$

permeability modeling of dual media reservoir, on the other hand, if the $\kappa$ is zero the dual permeability modeling of dual media reservoir is reduced to the modeling of homogenous reservoir. 


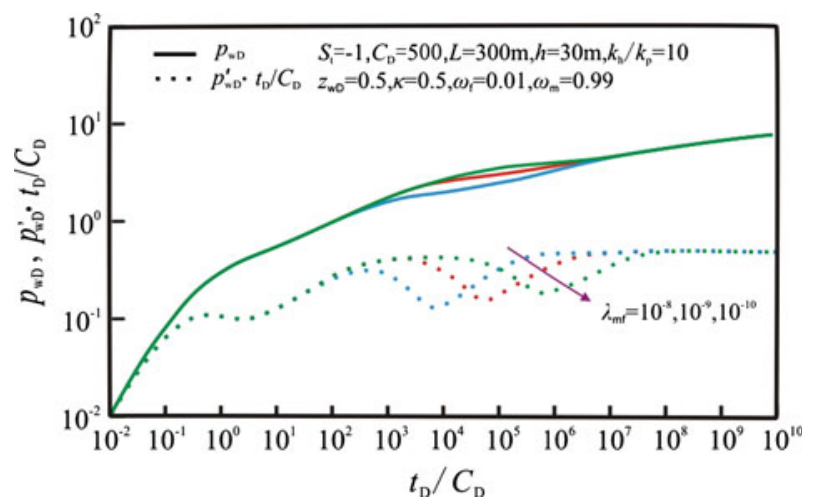

Fig. 13 Type curves of wellbore pressure response affected by $\lambda_{\mathrm{mf}}$

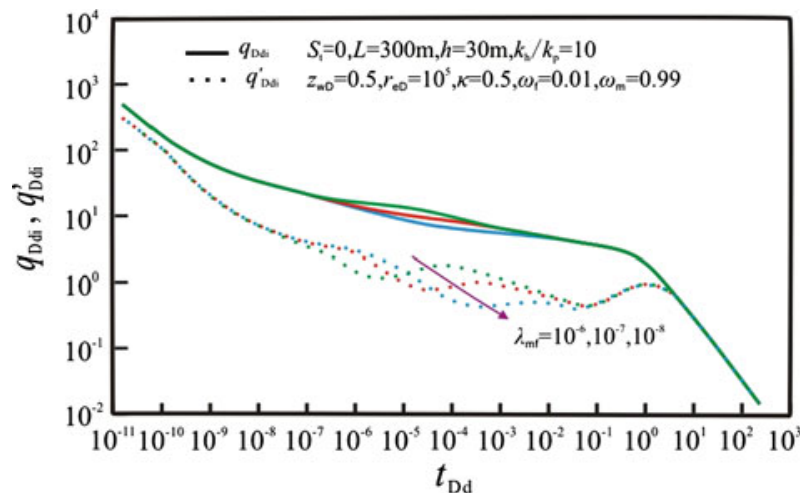

Fig. 14 Type curves of rate decline response affected by $\lambda_{\text {mf }}$

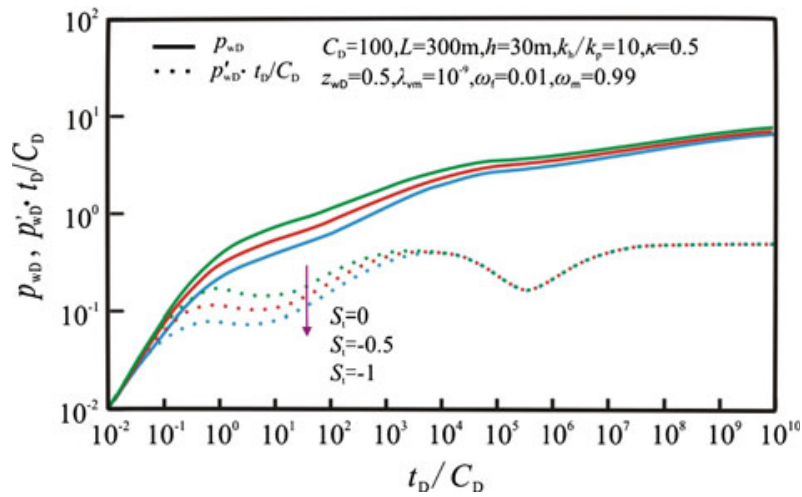

Fig. 15 Type curves of wellbore pressure response affected by $S$

Figures 11 and 12 show the type curves characteristics affected by fluid capacitance coefficients of fracture system $\omega_{\mathrm{f}}$. A bigger $\omega_{\mathrm{f}}$ leads to a shallower V-shaped concave. The $\omega_{\mathrm{f}}$ represents the relative capacity of fluid stored in reservoirs. A bigger $\omega_{\mathrm{f}}$ is the response of relative abundant reserves in fracture system. 


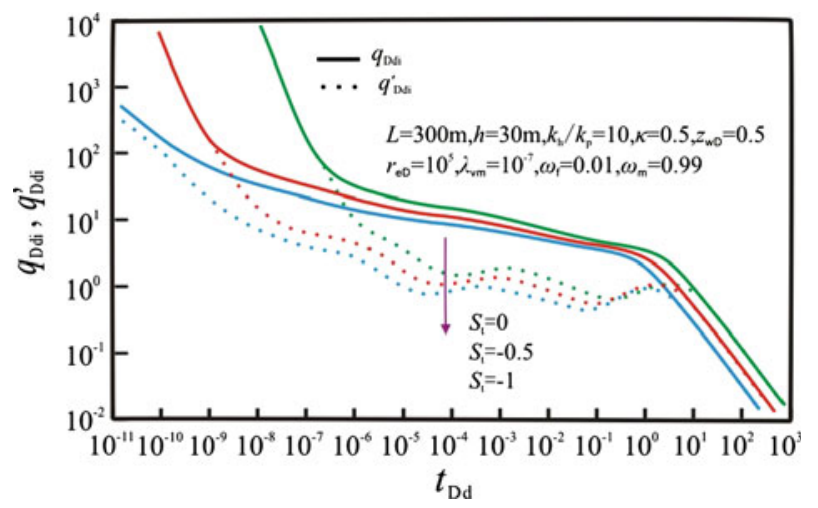

Fig. 16 Type curves of rate decline response affected by $S$

Figures 13 and 14 reflect the type curves characteristics affected by inter-porosity flow factor of matrix system to fracture system $\lambda_{\mathrm{mf}}$. According to the definition of $\lambda_{\mathrm{mf}}=$ $\alpha_{\mathrm{m}} k_{\mathrm{m}} r_{\mathrm{w}}^{2} /\left(k_{\mathrm{fh}}+k_{\mathrm{mh}}\right)$, the $\lambda_{\mathrm{mf}}$ is the function related to fracture permeability, matrix permeability, and the shape factor of matrix block. Because $\lambda_{\mathrm{mf}}$ represents the starting time of inter-porosity flow of matrix system to fracture system, so the bigger the $\lambda_{\mathrm{mf}}$ is, the earlier the time of inter-porosity is. Sometimes the early transition stage has not finished, the interporosity flow may be starting, just like the curves of " $\lambda_{\mathrm{mf}}=10^{-8 \text { " }}$ in Fig. 13 and the curves of " $\lambda_{\mathrm{mf}}=10^{-6 "}$ " in Fig. 14.

Figures 15 and 16 show the type curves characteristics affected by parameter $S$. It can be seen that skin factor influences dynamic response positively. The greater $S$ leads to higher location of dimensionless pressure curve. If there has a relative larger positive skin, the formation damage near the wellbore will be possibly more serious, then the reservoir could be stimulated by some treatments, and on the other hand, if there has a negative skin, the flow conditions near wellbore will be better. Accordingly, we can judge the effects of stimulations such as acidizing and hydraulic fracturing by the skin factor, after the comparison of the results from well testing interpretations before and after stimulation.

Our dual permeability modeling of horizontal well-production is suitable for various complex reservoirs with matrix-fracture dual-porosity properties, such as naturally fractured carbonate reservoirs, naturally fractured shale reservoirs and volcanite reservoirs, because the different reservoirs are only shown in the differences of parameter values. In addition, although the establishment of our modeling based on oil reservoirs, it still can be applied to gas reservoirs, because it has unified mathematical modeling for dimensionless definitions which is the only differences between oil and gas reservoirs (Jia 1993).

This dual porosity and dual permeability modeling of horizontal well in naturally fractured reservoir can be applied to real case study, and it will allow users to test models against a reference semi-analytical model.

\section{Conclusions}

Through our research, the complex dual porosity and dual permeability modeling of horizontal well production in a naturally fractured reservoir is established, solved, and the standard type curves of this model are obtained. The following conclusions can be drawn: 
(1) Our dual permeability modeling is more accurate than the traditional single permeability modeling because we considered the direct fluid supply from matrix to wellbore, which leads to the distinct differences in type curves.

(2) Four main flow stages can be observed. The differences between dual permeability and single permeability models are shown in the skin effect, early transition stage, and the inter-porosity flow stage of matrix system to fracture system.

(3) Type curves are dominated by inter-porosity flow factor, external boundary conditions and fluid capacitance coefficient, etc.

(4) The parameter $\kappa$ is used only for the dual permeability modeling. However, this model can be converted to the single permeability modeling by set $\kappa$ as one, or converted to homogenous reservoir modeling by set $\kappa$ as zero.

(5) This dual permeability modeling is suitable for various naturally fractured oil reservoirs or gas reservoirs, and the standard type curves show that it would be a good semi-analytical model to do real case study.

Acknowledgments The authors would like to thank the 4 anonymous reviewers. They thoroughly reviewed the manuscript and their critical comments were very helpful in preparing this article. The authors would like to also thank the editors of TIPM for their managing and editing the article. The authors would like to especially thank Mr Hong-Qiao Jia (an engineer of the company of SPT Group Inc. in Houston, Texas, U.S.A.) for his ardent help in English writing and usage.

Open Access This article is distributed under the terms of the Creative Commons Attribution Noncommercial License which permits any noncommercial use, distribution, and reproduction in any medium, provided the original author(s) and source are credited.

\section{Appendix A: Dimensionless Definitions}

The dimensionless definitions are as follows:

Fluid capacitance coefficient $\omega_{j}=\phi_{j} C_{j \mathrm{t}} /\left(\phi_{\mathrm{f}} C_{\mathrm{ft}}+\phi_{\mathrm{m}} C_{\mathrm{mt}}\right),(j=\mathrm{f}, \mathrm{m})$;

Inter-porosity flow factor of matrix system into fracture system $\lambda_{\mathrm{mf}}=\alpha_{\mathrm{m}} k_{\mathrm{m}} r_{\mathrm{w}}^{2} / k_{\mathrm{fh}}+$ $\left.k_{\mathrm{mh}}\right)$;

The permeability ratio of fracture system to the sum of fracture and matrix system $\kappa=$ $k_{\mathrm{fh}} /\left(k_{\mathrm{fh}}+k_{\mathrm{mh}}\right)$;

Dimensionless wellbore storage constant $C_{\mathrm{D}}=C_{\mathrm{s}} /\left(6.2832 \phi C_{\mathrm{t}} h r_{\mathrm{w}}^{2}\right)$;

Total Skin factor of horizontal well $S_{\mathrm{t}}=\sqrt{k_{\mathrm{h}} k_{\mathrm{p}}}(L / 2) \Delta p_{\mathrm{s}} /\left(1.842 \times 10^{-3} q \mu B\right)$, and $\Delta p_{\mathrm{s}}$ $(\mathrm{MPa})$ is the additional pressure drop near wellbore;

Skin factor similar to vertical well $S=k_{\mathrm{h}} h \Delta p_{s} /\left(1.842 \times 10^{-3} q \mu B\right)$;

The relationship of $S_{t}$ with $S \quad S_{\mathrm{t}}=L \sqrt{k_{\mathrm{p}} / k_{\mathrm{h}}} S /(2 h)$

Dimensionless radial distance $r_{\mathrm{D}}=r /\left(r_{\mathrm{w}} \mathrm{e}^{-S}\right)$;

Dimensionless formation thickness $h_{\mathrm{D}}=h \sqrt{k_{\mathrm{h}} / k_{\mathrm{p}}} /\left(r_{\mathrm{w}} \mathrm{e}^{-S}\right)$;

Dimensionless perpendicular distance $z_{\mathrm{D}}=z / h$;

Dimensionless perpendicular wellbore distance $z_{\mathrm{wD}}=z_{\mathrm{W}} / h$;

Dimensionless pressure:

For constant rate production $p_{j \mathrm{D}}=\left(k_{\mathrm{mh}}+k_{\mathrm{fh}}\right) h\left(p_{\mathrm{i}}-p_{j}\right) /\left(1.842 \times 10^{-3} q B \mu\right),(j=\mathrm{m}, \mathrm{f})$; For constant wellbore pressure production $p_{j \mathrm{D}}=\left(p_{\mathrm{i}}-p_{j}\right) /\left(p_{\mathrm{i}}-p_{\mathrm{w}}\right),(j=\mathrm{m}, \mathrm{f})$;

Dimensionless production time $t_{\mathrm{D}}=3.6\left(k_{\mathrm{mh}}+k_{\mathrm{fh}}\right) t /\left[\mu r_{\mathrm{w}}^{2}\left(\phi_{\mathrm{m}} C_{\mathrm{mt}}+\phi_{\mathrm{f}} C_{\mathrm{ft}}\right)\right]$;

Decline curve dimensionless time of Blasingame $t_{\mathrm{Dd}}=t_{\mathrm{D}} /\left[\left(r_{\mathrm{eD}}^{2}-1\right)\left(\ln \left(r_{\mathrm{eD}}\right)-0.5\right) / 2\right]$;

Dimensionless rate $q_{\mathrm{D}}=1.842 \times 10^{-3} q B \mu /\left[\left(k_{\mathrm{mh}}+k_{\mathrm{fh}}\right) h\left(p_{\mathrm{i}}-p_{\mathrm{w}}\right)\right]$; 
Decline curve dimensionless rate of Blasingame $q_{\mathrm{Dd}}=q_{\mathrm{D}}\left[\ln \left(r_{\mathrm{eD}}\right)-0.5\right]$;

Dimensionless rate integral function of Blasingame $q_{\mathrm{Ddi}}=\left[\int_{0}^{t_{\mathrm{Dd}}} q_{\mathrm{Dd}}(\tau) \mathrm{d} \tau\right] / t_{\mathrm{Dd}}$;

Dimensionless rate integral derivative function of Blasingame $q_{\mathrm{Ddi}}^{\prime}=-\frac{\mathrm{d} q_{\mathrm{Ddi}}}{\mathrm{d} \ln t_{\mathrm{Dd}}}=$ $-t_{\mathrm{Dd}} \frac{\mathrm{d} q_{\mathrm{Ddi}}}{\mathrm{d} t_{\mathrm{Dd}}}$

\section{Appendix B: Solving the Mathematic Model}

Separation of Variables

Equations 2 and 3 can be expressed, respectively, by

$$
\begin{aligned}
& \frac{\partial^{2} \bar{p}_{\mathrm{fD}}}{\partial r_{\mathrm{D}}^{2}}+\frac{1}{r_{\mathrm{D}}} \frac{\partial \bar{p}_{\mathrm{fD}}}{\partial r_{\mathrm{D}}}+\frac{1}{h_{\mathrm{D}}^{2}} \frac{\partial^{2} \bar{p}_{\mathrm{fD}}}{\partial z_{\mathrm{D}}^{2}}+\frac{m_{1}}{\kappa} \bar{p}_{\mathrm{fD}}+\frac{m_{2}}{\kappa} \bar{p}_{\mathrm{mD}}=0 \\
& \frac{\partial^{2} \bar{p}_{\mathrm{mD}}}{\partial r_{\mathrm{D}}^{2}}+\frac{1}{r_{\mathrm{D}}} \frac{\partial \bar{p}_{\mathrm{mD}}}{\partial r_{\mathrm{D}}}+\frac{1}{h_{\mathrm{D}}^{2}} \frac{\partial^{2} \bar{p}_{\mathrm{mD}}}{\partial z_{\mathrm{D}}^{2}}+\frac{m_{2}}{(1-\kappa)} \bar{p}_{\mathrm{fD}}+\frac{m_{3}}{(1-\kappa)} \bar{p}_{\mathrm{mD}}=0 \\
& m_{1}=-\left(\lambda_{\mathrm{mf}}+u \omega_{\mathrm{f}}\right) \mathrm{e}^{-2 S}, m_{2}=\lambda_{\mathrm{mf}} \mathrm{e}^{-2 S}, m_{3}=-\left(\lambda_{\mathrm{mf}}+u \omega_{\mathrm{m}}\right) \mathrm{e}^{-2 S}
\end{aligned}
$$

By use of the method of separation of variables, the model can be solved. The dimensionless pressures in Laplace space can be separated by

$$
\begin{aligned}
\bar{p}_{\mathrm{fD}} & =\bar{R}_{\mathrm{f}}\left(r_{\mathrm{D}}\right) \bar{Z}_{\mathrm{f}}\left(z_{\mathrm{D}}\right) \\
\bar{p}_{\mathrm{mD}} & =\bar{R}_{\mathrm{m}}\left(r_{\mathrm{D}}\right) \bar{Z}_{\mathrm{m}}\left(z_{\mathrm{D}}\right)
\end{aligned}
$$

Substitute Eq. B.4 into Eq. B.1, have

$$
h_{\mathrm{D}}^{2}\left(\bar{R}_{\mathrm{f}}^{\prime \prime}+\frac{1}{r_{\mathrm{D}}} \bar{R}_{\mathrm{f}}^{\prime}-\sigma \bar{R}_{\mathrm{f}}\right) / \bar{R}_{\mathrm{f}}=-\bar{Z}_{\mathrm{f}}^{\prime \prime} / \bar{Z}_{\mathrm{f}}=\lambda
$$

where, the $\sigma$ must be the function of relating to $m_{1}, m_{2}, m_{3}$, and $\kappa$.

So

$$
\begin{aligned}
& \bar{R}_{\mathrm{f}}^{\prime \prime}+\frac{1}{r_{\mathrm{D}}} \bar{R}_{\mathrm{f}}^{\prime}-\xi \bar{R}_{\mathrm{f}}=0 \\
& \xi=\sigma+\frac{\lambda}{h_{\mathrm{D}}^{2}} \\
& \bar{Z}_{\mathrm{f}}^{\prime \prime}+\lambda \bar{Z}_{\mathrm{f}}=0
\end{aligned}
$$

By the same method, have

$$
\begin{aligned}
& \bar{R}_{\mathrm{m}}^{\prime \prime}+\frac{1}{r_{\mathrm{D}}} \bar{R}_{\mathrm{m}}^{\prime}-\xi \bar{R}_{\mathrm{m}}=0 \\
& \bar{Z}_{\mathrm{m}}^{\prime \prime}+\lambda \bar{Z}_{\mathrm{m}}=0
\end{aligned}
$$


Solutions in horizontal direction

If there is no flow in vertical $z$ direction, Eqs. B.1 and B.2 would become

$$
\begin{aligned}
& \frac{\partial^{2} \bar{R}_{\mathrm{fD}}}{\partial r_{\mathrm{D}}^{2}}+\frac{1}{r_{\mathrm{D}}} \frac{\partial \bar{R}_{\mathrm{fD}}}{\partial r_{\mathrm{D}}}+\frac{m_{1}}{\kappa} \bar{R}_{\mathrm{fD}}+\frac{m_{2}}{\kappa} \bar{R}_{\mathrm{mD}}=0 \\
& \frac{\partial^{2} \bar{R}_{\mathrm{mD}}}{\partial r_{\mathrm{D}}^{2}}+\frac{1}{r_{\mathrm{D}}} \frac{\partial \bar{R}_{\mathrm{mD}}}{\partial r_{\mathrm{D}}}+\frac{m_{2}}{(1-\kappa)} \bar{R}_{\mathrm{fD}}+\frac{m_{3}}{(1-\kappa)} \bar{R}_{\mathrm{mD}}=0
\end{aligned}
$$

The general solutions of Eqs. B.12 and B.13

$$
\begin{aligned}
& \bar{R}_{\mathrm{f}}=A_{\mathrm{f}} \mathrm{I}_{0}\left(\sqrt{\sigma} r_{\mathrm{D}}\right)+B_{\mathrm{f}} \mathrm{K}_{0}\left(\sqrt{\sigma} r_{\mathrm{D}}\right) \\
& \bar{R}_{\mathrm{m}}=A_{\mathrm{m}} \mathrm{I}_{0}\left(\sqrt{\sigma} r_{\mathrm{D}}\right)+B_{\mathrm{m}} \mathrm{K}_{0}\left(\sqrt{\sigma} r_{\mathrm{D}}\right)
\end{aligned}
$$

Under infinite external boundary of side, have

$$
A_{\mathrm{f}}=A_{\mathrm{m}}=0
$$

where $A_{\mathrm{f}}, A_{\mathrm{m}}, B_{\mathrm{f}}$, and $B_{\mathrm{m}}$ are the undetermined coefficients; $\mathrm{I}_{0}()=$ modified Bessel function of the first kind, zero order; $\mathrm{K}_{0}()=$ modified Bessel function of the second kind, zero order.

Because the modeling must have solutions, the coefficients $B_{\mathrm{m}}$ and $B_{\mathrm{f}}$ cannot be zero, so substitute Eqs. B.14-B.16 into Eqs. B.12 and B.13, have

$$
\sigma=\frac{-\left[\kappa m_{3}+(1-\kappa) m_{1}\right] \pm \sqrt{\left[\kappa m_{3}+(1-\kappa) m_{1}\right]^{2}-4 \kappa(1-\kappa)\left(m_{1} m_{3}-m_{2}^{2}\right)}}{2 \kappa(1-\kappa)}
$$

If the two roots of Eq. B.17 are $\sigma_{1}$ and $\sigma_{2}$, the general solutions of Eqs. B.12 and B.13 are

$$
\begin{aligned}
\bar{R}_{\mathrm{f}} & =A_{\mathrm{f}, 1} \mathrm{I}_{0}\left(\sqrt{\sigma_{1}} r_{\mathrm{D}}\right)+A_{\mathrm{f}, 2} \mathrm{I}_{0}\left(\sqrt{\sigma_{2}} r_{\mathrm{D}}\right)+B_{\mathrm{f}, 1} \mathrm{~K}_{0}\left(\sqrt{\sigma_{1}} r_{\mathrm{D}}\right)+B_{\mathrm{f}, 2} \mathrm{~K}_{0}\left(\sqrt{\sigma_{2}} r_{\mathrm{D}}\right) \\
\bar{R}_{\mathrm{m}} & =A_{\mathrm{m}, 1} \mathrm{I}_{0}\left(\sqrt{\sigma_{1}} r_{\mathrm{D}}\right)+A_{\mathrm{m}, 2} \mathrm{I}_{0}\left(\sqrt{\sigma_{2}} r_{\mathrm{D}}\right)+B_{\mathrm{m}, 1} \mathrm{~K}_{0}\left(\sqrt{\sigma_{1}} r_{\mathrm{D}}\right)+B_{\mathrm{m}, 2} \mathrm{~K}_{0}\left(\sqrt{\sigma_{2}} r_{\mathrm{D}}\right)
\end{aligned}
$$

where $A_{\mathrm{f}, 1}, A_{\mathrm{f}, 2}, A_{\mathrm{m}, 1}, A_{\mathrm{m}, 2}, B_{\mathrm{f}, 1}, B_{\mathrm{f}, 2}, B_{\mathrm{m}, 1}$, and $B_{\mathrm{m}, 2}$ are the undetermined coefficients.

Substitute Eqs. B.18 and B.19 into Eq. B.12, and note the model must have solutions for a fixed $r_{\mathrm{D}}$ in formation, the Bessel functions must not be zero, so the following relationships can be derived

$$
\begin{aligned}
A_{\mathrm{m}, 1} & =a_{1} A_{\mathrm{f}, 1}, A_{\mathrm{m}, 2}=a_{2} A_{\mathrm{f}, 2}, B_{\mathrm{m}, 1}=a_{1} B_{\mathrm{f}, 1}, B_{\mathrm{m}, 2}=a_{2} B_{\mathrm{f}, 2} \\
a_{1} & =-\left(\kappa \sigma_{1}+m_{1}\right) / m_{2}, a_{2}=-\left(\kappa \sigma_{2}+m_{1}\right) / m_{2}
\end{aligned}
$$

For horizontal well, the flow in vertical $z$ direction must be considered, so the general solutions of Eqs. B.12 and B.13 are

$$
\begin{aligned}
\bar{R}_{\mathrm{f}} & =A_{\mathrm{f}, 1} \mathrm{I}_{0}\left(\sqrt{\xi_{1}} r_{\mathrm{D}}\right)+A_{\mathrm{f}, 2} \mathrm{I}_{0}\left(\sqrt{\xi_{2}} r_{\mathrm{D}}\right)+B_{\mathrm{f}, 1} \mathrm{~K}_{0}\left(\sqrt{\xi_{1}} r_{\mathrm{D}}\right)+B_{\mathrm{f}, 2} \mathrm{~K}_{0}\left(\sqrt{\xi_{2}} r_{\mathrm{D}}\right) \\
R_{\mathrm{m}} & =a_{1} A_{\mathrm{f}, 1} \mathrm{I}_{0}\left(\sqrt{\xi_{1}} r_{\mathrm{D}}\right)+a_{2} A_{\mathrm{f}, 2} \mathrm{I}_{0}\left(\sqrt{\xi_{2}} r_{\mathrm{D}}\right)+a_{1} B_{\mathrm{f}, 1} \mathrm{~K}_{0}\left(\sqrt{\xi_{1}} r_{\mathrm{D}}\right)+a_{2} B_{\mathrm{f}, 2} \mathrm{~K}_{0}\left(\sqrt{\xi_{2}} r_{\mathrm{D}}\right) \\
\xi_{1} & =\sigma_{1}+\frac{\lambda}{h_{\mathrm{D}}^{2}}, \xi_{2}=\sigma_{2}+\frac{\lambda}{h_{\mathrm{D}}^{2}}
\end{aligned}
$$

Now firstly seek the solution to constant rate production: 
Substitute Eqs. B.22 and B.23 into the well-production condition Eqs. 4 and 5, have

$$
\begin{aligned}
& \left(1-a_{1}\right) \mathrm{I}_{0}\left(\sqrt{\xi_{1}}\right) A_{\mathrm{f}, 1}+\left(1-a_{2}\right) I_{0}\left(\sqrt{\xi_{2}}\right) A_{\mathrm{f}, 2}+\left(1-a_{1}\right) \mathrm{K}_{0}\left(\sqrt{\xi_{1}}\right) B_{\mathrm{f}, 1} \\
& \quad+\left(1-a_{2}\right) \mathrm{K}_{0}\left(\sqrt{\xi_{2}}\right) B_{\mathrm{f}, 2}=0 \\
& {\left[\kappa+(1-\kappa) a_{1}\right] B_{\mathrm{f}, 1}+\left[\kappa+(1-\kappa) a_{2}\right] B_{\mathrm{f}, 2}=\frac{1}{u}}
\end{aligned}
$$

Substitute Eqs. B.22 and B.23 into the side external boundary conditions Eqs. 11, 12, and 13, have:

For infinite boundary

$$
\begin{gathered}
A_{\mathrm{f}, 1}=A_{\mathrm{f}, 2}=0 \\
B_{\mathrm{f}, 2}=\frac{1}{u} \frac{\left(1-a_{1}\right) \mathrm{K}_{0}\left(\sqrt{\xi_{1}}\right)}{\left[\kappa+(1-\kappa) a_{2}\right]\left(1-a_{1}\right) \mathrm{K}_{0}\left(\sqrt{\xi_{1}}\right)-\left[\kappa+(1-\kappa) a_{1}\right]\left(1-a_{2}\right) \mathrm{K}_{0}\left(\sqrt{\xi_{2}}\right)} \\
B_{\mathrm{f}, 1}=\frac{1}{\left[\kappa+(1-\kappa) a_{1}\right] u}-\frac{\kappa+(1-\kappa) a_{2}}{\kappa+(1-\kappa) a_{1}} B_{\mathrm{f}, 2}
\end{gathered}
$$

For constant pressure boundary

$$
\begin{aligned}
& \mathrm{I}_{0}\left(\sqrt{\xi_{1}} r_{\mathrm{eD}}\right) A_{\mathrm{f}, 1}+\mathrm{I}_{0}\left(\sqrt{\xi_{2}} r_{\mathrm{eD}}\right) A_{\mathrm{f}, 2}+\mathrm{K}_{0}\left(\sqrt{\xi_{1}} r_{\mathrm{eD}}\right) B_{\mathrm{f}, 1}+\mathrm{K}_{0}\left(\sqrt{\xi_{2}} r_{\mathrm{eD}}\right) B_{\mathrm{f}, 2}=0 \\
& a_{1} \mathrm{I}_{0}\left(\sqrt{\xi_{1}} r_{\mathrm{eD}}\right) A_{\mathrm{f}, 1}+a_{2} \mathrm{I}_{0}\left(\sqrt{\xi_{2}} r_{\mathrm{eD}}\right) A_{\mathrm{f}, 2}+a_{1} \mathrm{~K}_{0}\left(\sqrt{\xi_{1}} r_{\mathrm{eD}}\right) B_{\mathrm{f}, 1}+a_{2} \mathrm{~K}_{0}\left(\sqrt{\xi_{2}} r_{\mathrm{eD}}\right) B_{\mathrm{f}, 2}=0
\end{aligned}
$$

For closed boundary

$$
\begin{aligned}
& \sqrt{\xi_{1}} \mathrm{I}_{1}\left(\sqrt{\xi_{1}} r_{\mathrm{eD}}\right) A_{\mathrm{f}, 1}+\sqrt{\xi_{2}} \mathrm{I}_{1}\left(\sqrt{\xi_{2}} r_{\mathrm{eD}}\right) A_{\mathrm{f}, 2}-\sqrt{\xi_{1}} \mathrm{~K}_{1}\left(\sqrt{\xi_{1}} r_{\mathrm{eD}}\right) B_{\mathrm{f}, 1} \\
& -\sqrt{\xi_{2}} \mathrm{~K}_{1}\left(\sqrt{\xi_{2}} r_{\mathrm{eD}}\right) B_{\mathrm{f}, 2}=0 \\
& a_{1} \sqrt{\xi_{1}} \mathrm{I}_{1}\left(\sqrt{\xi_{1}} r_{\mathrm{eD}}\right) A_{\mathrm{f}, 1}+a_{2} \sqrt{\xi_{2}} \mathrm{I}_{1}\left(\sqrt{\xi_{2}} r_{\mathrm{eD}}\right) A_{\mathrm{f}, 2}-a_{1} \sqrt{\xi_{1}} \mathrm{~K}_{1}\left(\sqrt{\xi_{1}} r_{\mathrm{eD}}\right) B_{\mathrm{f}, 1} \\
& -a_{2} \sqrt{\xi_{2}} \mathrm{~K}_{0}\left(\sqrt{\xi_{2}} r_{\mathrm{eD}}\right) B_{\mathrm{f}, 2}=0
\end{aligned}
$$

where $\mathrm{I}_{1}()=$ modified Bessel function of the first kind, first order; $\mathrm{K}_{1}()=$ modified Bessel function of the second kind, first order.

For constant pressure and closed boundary, there are four equations, so the four coefficients $\left(A_{\mathrm{f}, 1}, A_{\mathrm{f}, 2}, B_{\mathrm{f}, 1}, B_{\mathrm{f}, 2}\right)$ can easily obtained by computer calculation program.

\section{Solutions in Vertical Direction}

The general solution of Eq. B.9 is

$$
\bar{Z}_{\mathrm{f}}=C \cos \left(\sqrt{\lambda} z_{\mathrm{D}}\right)+D \sin \left(\sqrt{\lambda} z_{\mathrm{D}}\right)
$$

(1) Closed boundary for both top and bottom

Substitute Eq. B.34 into Eqs. 7 and 9, have

$$
D=0, \lambda=\lambda_{n}=(n \pi)^{2}, n=0,1,2 \ldots
$$

where $\lambda$ is the eigenvalue of eigenfunction $\cos \left(\sqrt{\bar{\lambda}} z_{\mathrm{D}}\right)$.

The $C$ is relevant to the eigenvalue, eigenfunction and the relative location of horizontal wellbore $z_{\mathrm{wD}}$, in addition, $C$ depends on the production manner of horizontal well. For constant rate production, in the infinite acting pseudo-radial flow stage, the pressure derivative 
curves must be the radial flow zero slope. It is found that Eq. B.36 completely satisfies the conditions.

$$
C=\frac{1}{2} \cos \left(\sqrt{\lambda_{n}} z_{\mathrm{wD}}\right), \lambda_{n}=(n \pi)^{2}, n=0,1,2 \ldots
$$

So the solutions in vertical direction are

$$
\bar{Z}_{\mathrm{fn}}=\frac{1}{2} \cos \left(\sqrt{\lambda_{n}} z_{\mathrm{wD}}\right) \cos \left(\sqrt{\lambda_{n}} z_{\mathrm{D}}\right), \lambda_{n}=(n \pi)^{2}, n=0,1,2 \ldots
$$

(2) Constant pressure boundary for both top and bottom

By the same method, the solutions in vertical direction are

$$
\bar{Z}_{\mathrm{f}} n=\frac{1}{2} \sin \left(\sqrt{\lambda_{n}} z_{\mathrm{wD}}\right) \sin \left(\sqrt{\lambda} z_{\mathrm{D}}\right), \lambda_{n}=(n \pi)^{2}, n=0,1,2 \ldots
$$

(3) Closed boundary for top and constant pressure boundary for bottom

$$
\bar{Z}_{\mathrm{f}} n=\frac{1}{2} \sin \left(\sqrt{\lambda_{n}} z_{\mathrm{wD}}\right) \sin \left(\sqrt{\lambda_{n}} z_{\mathrm{D}}\right), \lambda_{n}=\left[\left(n-\frac{1}{2}\right) \pi\right]^{2}, n=0,1,2 \ldots
$$

(4) Constant pressure boundary for top and closed boundary for bottom

$$
\bar{Z}_{\mathrm{f}} n=\frac{1}{2} \cos \left(\sqrt{\lambda_{n}} z_{\mathrm{wD}}\right) \cos \left(\sqrt{\lambda_{n}} z_{\mathrm{D}}\right), \lambda_{n}=\left[\left(n-\frac{1}{2}\right) \pi\right]^{2}, n=0,1,2 \ldots
$$

\section{References}

Algharaib, M., Gharbi, R., Malallah, A.: Scaling immiscible displacements in porous media with horizontal wells. Trans. Porous Med. 65(1), 89-105 (2006). doi:10.1007/s11242-005-6089-0

Al-Ghamdi, A., Ershaghi, I.: Pressure transient analysis of dually fractured reservoirs. SPE 26959-PA. SPE J. 1(1), 93-100 (1996). doi:10.2118/26959-PA

Al-Shaalan, T.M., Fung, L.S.K., Dogru, A.H.: A scalable massively parallel dual-porosity dual-permeability simulator for fractured reservoirs with super-k permeability. SPE 84371-MS, presented at the SPE annual technical conference and exhibition held in Denver, Colorado, 5-8 Oct 2003. doi:10.2118/84371-MS

Blasingame, T.A., McCray, T.L., Lee, W.J.: Decline curve analysis for variable pressure drop/variable flowrate systems. Paper SPE 21513 presented at the SPE gas technology symposium, Houston, 22-24 Jan 1991. doi:10.2118/21513-MS

Boughrara, A.A., Reynolds, A.C.: Analysis of injection/falloff data from horizontal wells. SPE-109799PA. SPE J. 14(4), 721-736 (2009). doi:10.2118/109799-PA

Bourdet, D.: Well test analysis: The use of advanced interpretation models. pp. 426 Elsevier Science B.V., Amsterdam (2002)

Braester, C.: Influence of block size on the transition curve for a drawdown test in a naturally fractured reservoir. SPE 10543-PA. SPE J. 24(5), 498-504 (1984). doi:10.2118/10543-PA

Braester, C., Zeitoun, D.G.: Pressure transient response of stochastically heterogeneous fractured reservoirs. Trans. Porous Med. 11(3), 263-280 (1993). doi:10.1007/BF00614815

Bui, T.D., Mamora, D.D., Lee, W.J.: Transient pressure analysis for partially penetrating wells in naturally fractured reservoirs. SPE 60289-MS, presented at the 2000 SPE rocky mountain regional/low permeability reservoirs symposium and exbibition held in Denver, Colorado, 12-15 Mar 2000. doi:10.2118/ 60289-MS

Chastanet, J., Royer, P., Auriault, J.-L.: Flow of low pressure gas through dual-porosity media. Trans. Porous Med. 66(3), 457-479 (2007). doi:10.1007/s11242-006-0023-y

Chen, Z.X.: Transient flow of slightly compressible fluids through double-porosity, double-permeability systems-a state-of-the-art review. Trans. Porous Med. 4(2), 147-184 (1989). doi:10.1007/BF00134995

Corbett, P.W.M., Geiger, S., Borges, L., Garayev, M., Gonzalez, J., Camilo, V.: Limitations in the numerical well test modelling of fractured carbonate rocks, SPE 130252-MS. Presented at Europec/EAGE annual conference and exhibition, Barcelona, 14-17 June 2010. doi:10.2118/130252-MS 
Degraff, J.M., Meurer, M.E., Landis, L.H., Lyons, S.: Fracture network modeling and dual-permeability simulation of carbonate reservoirs. SPE 10954-MS. Presented at the international petroleum technology conference held in Doha, Qatar, 21-23 Nov 2005. doi:10.2118/10954-MS

De Swaan, O.A.: Analytical solutions for determining naturally fractured reservoir properties by well testing. SPE 5346-PA. SPE J. 16(3), 117-122 (1976). doi:10.2118/5346-PA

Doublet, L.E., Blasingame, T.A.: Decline curve analysis using type curves-analysis of oil well production data using material balance time: application to field cases. Paper SPE 28688 Presented at the petroleum conference and exhibition of Mexico, Veracruz, 10-13 Oct 1994. doi:10.2118/28688-MS

Du, K.F., Stewart, G.: Transient pressure response of horizontal wells in layered and naturally fractured reservoirs with dual-porosity behavior. Paper SPE 24682 presented at the SPE Annual Technical Conference and Exhibition, Washington, 4-7 Oct 1992. doi:10.2118/24682-MS

Duan, Y.G., Chen, W., Li, Q.S.: A comprehensive well test model for horizontal wells with complex boundaries. Paper PETSOC 98-21 presented at the Annual Technical Meeting, Calgary, 8-10 June 1998. doi:10. 2118/98-21

Frick, T.P., Brand, C.W., Schlager, B., Economides, M.J.: Horizontal well testing of isolated segments. SPE 29959-PA. SPE J. 1(3), 261-274 (1996). doi:10.2118/29959-PA

Gill, H., Issaka, M.B.: Pressure transient behavior of horizontal and slant wells intersecting a high-permeability layer. Paper SPE 105616 presented at the SPE middle east oil and gas show and conference, Denver, 11-14 Mar 2007. doi:10.2118/105616-MS

Goode, P.A., Thambynayagam, R.K.M.: Pressure drawdown and buildup analysis of horizontal wells in anisotropic media. SPE 14250-PA. SPE Form. Eval. 2(4), 683-697 (1987). doi:10.2118/14250-PA

Hashemi, A., Nicolas, L.M., France, G.D., Gringarten, A.C.: Well test analysis of horizontal wells in gas-condensate reservoirs. SPE 89905-PA. SPE Reserv. Eval. Eng. 9(1), 86-99 (2006). doi:10.2118/ 89905-PA

Huang, C.S., Chen, Y.L., Yeh, H.D.: A general analytical solution for flow to a single horizontal well by fourier and laplace transforms. Adv. Wat. Resour. 34(5), 640-648 (2011). doi:10.1016/j.advwatres.2011.02.015

Hu, B.X., Huang, H.: Stochastic analysis of reactive solute transport in heterogeneous, fractured porous media: a dual-permeability approach. Trans. Porous Med. 48(1), 1-39 (2002). doi:10.1023/A:1015671227317

Jia, Y.: The unity of well test analysis equations used for gas and oil wells respectively. Well Test. 2(4), 47-50 (1993) (in Chinese)

Jalali, Y., Ershaghi, I.: Pressure transient analysis of heterogeneous naturally fractured reservoirs. SPE 16341MS, presented at the SPE California regional meeting held in Ventura, California, 8-10 Apr (1987). doi:10.2118/16341-MS

Kawecki, M.W.: Transient flow to a horizontal water well. Gr. Wat. 38(6), 842-850 (2000)

Kompani-Zare, M., Zhan, H., Samani, N.: Analytical study of capture zone of a horizontal well in a confined aquifer. J. Hydrol. 307(1-4), 48-59 (2005). doi:10.1016/j.hydrol.2004.09.021

Kuchuk, E.J., Goode, P.A., Wilkinson, D.J., Thambynayagam, R.K.M.: Pressure-transient behavior of horizontal wells with and without gas cap or aquifer. SPE 17413-PA. SPE Form. Eval. 6(1), 86-94 (1991). doi:10.2118/17413-PA

Kuchuk, E.J., Hbashy, T.: Pressure behavior of horizontal wells in multilayer reservoirs with cross flow. SPE 22731-PA. SPE Form. Eval. 11(1), 55-64 (1996). doi:10.2118/22731-PA

Langseth, D.E., Smyth, A.H., May, J.: A method for evaluating horizontal well pumping tests. Gr. Wat. 42(5), 689-699 (2004)

Li, K. Horne, Roland, N.: Method to evaluate the potential of water injection in naturally fractured reservoirs. Trans. Porous Med. 83(3), 699-709 (2010). doi:10.1007/s11242-009-9473-3

Marhaendrajana, T., Blasingame, T.A.: Decline curve analysis using type curves-evaluation of well proformance behavior in a multiwell reservoir system. Paper SPE 71517 presented at the SPE annual technical conference and exhibition, New Orleans, 30 September-3 October 2001. doi:10.2118/71517-MS

Mattar, L., Santo, M.: A practical and systematic approach to horizontal well test analysis. PETSOC 95-0904. J. Can. Petroleum Technol. 34(9), 42-46 (1995). doi:10.2118/95-09-04

Ng, M.G., Aguilera, R.: Well test analysis of horizontal wells in bounded naturally fractured reservoirs. PETSOC 94-14. J. Can. Petroleum Technol. 38(7), 20-24 (1999). doi:10.2118/94-14

Nie, R.S., Ding, Y.: Research on the nonlinear spherical percolation model with quadratic pressure gradient and its percolation characteristics. Nat. Sci. 2(2), 98-105 (2010). doi:10.4236/ns.2010.22016

Nie, R., Meng, Y., Yang, Z., Guo, J., Jia, Y.: New flow model for the triple media carbonate reservoir. Int. J. Comput. Fluid Dyn. 25(2), 95-103 (2011). doi:10.1080/10618562.2011.560573

Ozkan, E.: Analysis of horizontal-well responses: contemporary vs. conventional. SPE 72494-PA. SPE Reserv. Eval. Eng. 4(4), 260-269 (2001). doi:10.2118/72494-PA

Ozkan, E., Raghavan, R., Joshi, S.D.: Horizontal-well pressure analysis. SPE 16378-PA. SPE Form. Eval. 4(4), 567-575 (1989). doi:10.2118/16378-PA 
Ozkan, E., Raghavan, R.: New solutions for well-test-analysis problems: Part 1-analytical considerations. SPE 18615-PA. SPE Form. Eval. 6(3), 359-368 (1991). doi:10.2118/18615-PA

Ozkan, E., Raghavan, R.: New solutions for well-test-analysis problems: part 2-conputational considerations and applications. SPE 18616-PA. SPE Form. Eval. 6(3), 369-378 (1991). doi:10.2118/18616-PA

Peres, A.M.M., Reynolds, A.C.: Theory and analysis of injectivity tests on horizontal well. SPE 84957-PA. SPE J. 8(2), 147-159 (2003). doi:10.2118/84957-PA

Sherrard, D.W.: Prediction and evaluation of horizontal well performance. Petroleum Geosci. 1(1), 2530 (1995). doi:10.1144/petgeo.1.1.25

Sheng, J.J.: Analytical steady-state solution of single-probe tests in a horizontal well and its application to estimate horizontal and vertical permeabilities. SPE 102659-PA. SPE Reserv. Eval. Eng. 11(3), 590597 (2008). doi:10.2118/102659-PA

Stehfest, H.: Numerical inversion of Laplace transform-algorithm 368. Commun. ACM 13(1), 47-49 (1970)

Sun, D., Zhan, H.: Flow to a horizontal well in an aquitard-aquifer system. J. Hydrol. 321(1-4), 364-376 (2006). doi:10.1016/j.jhydrol.2005.08.008

Uba, H.M., Chiffoleau, Y., Pham, T., Divry, V., Kaabi, A., Thuwaini, J.: Application of a hybrid dual-porosity/ dual-permeability representation of large-scale fractures to the simulation of a giant carbonate reservoir. SPE 105560-MS, presented at the SPE middle east oil and gas show and conference held in kingdom of Bahrain, Bahrain, 11-14 Mar 2007. doi:10.2118/105560-MS

Van Everdingen, A.F., Hurst, W.: The application of the laplace transformation to flow problems in reservoir. Trans. AIME 186, 305 (1949)

Van Heel, A.P.G., Boerrigter, P.M., Van Dorp, J.J.: Thermal and hydraulic matrix-fracture interaction in dualpermeability simulation. SPE 102471-PA. SPE Reserv. Eval. Eng. 11(4), 735-749 (2008). doi:10.2118/ 102471-PA

Warren, J.E., Root, P.J.: The behavior of naturally fractured reservoirs. SPE 426-PA. SPE J. 3(3), 245255 (1963). doi:10.2118/426-PA

Zhan, H., Zlotnik, V.A.: Ground water flow to horizontal and slanted wells in unconfined aquifers. Wat. Resour. Res. 38(7), 1108 (2002). doi:10.1029/2001WR000401 